\title{
From Resting State to the Steady State: Mechanistic Studies of Ene-Yne Metathesis Promoted by the Hoveyda Complex
}

\author{
Justin R. Griffiths, Jerome B. Keister*, and Steven T. Diver* \\ Department of Chemistry \\ University at Buffalo, the State University of New York, Buffalo, NY, 14260
}

\section{SUPPORTING INFORMATION}

Table of Contents

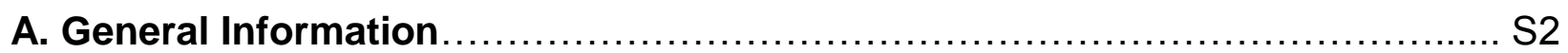

B. Kinetic Procedures - Ene-yne Metathesis.................................. S2

C. Validation of in situ IR Method.................................................. 3

D. Order in Reactants and Precatalyst ............................................. 5

E. Dual Spectroscopic Measurements ......................................... S15

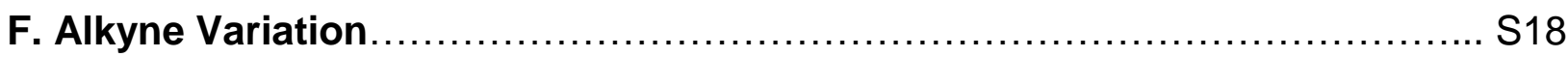

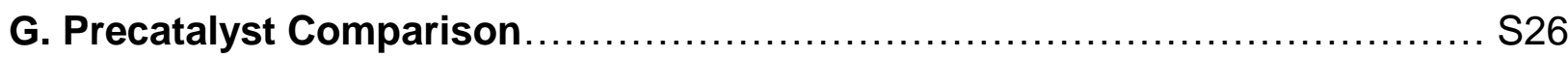

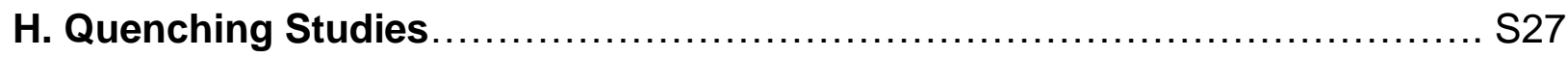

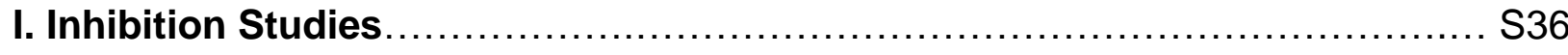

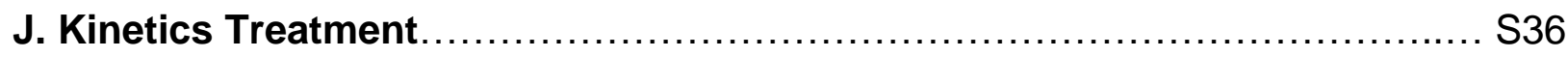

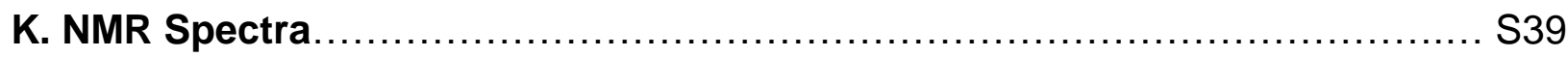




\section{A. General Information}

Unless otherwise stated, reactions were conducted with oven-dried glassware under an atmosphere of nitrogen. Solvent (toluene) was passed through alumina and Q5 (Anhydrous Engineering solvent purifier) and stored under nitrogen. The Hoveyda II ruthenium carbene complex (Ru1) was obtained from Materia Inc. (Pasadena, CA) and used as received. The Grela complex (Ru2) was also obtained from Materia Inc. (Pasadena, CA) and purified prior to use by column chromatography with EtOAc/hexanes. All alkynes were synthesized by previously reported literature procedures and purified prior to use by column chromatography $\left(\mathbf{1 A}^{1}, \mathbf{1 B}^{2}\right)$ with EtOAc/hexanes or distillation $\left(\mathbf{1 C}^{1}, \mathbf{2} \mathbf{A}^{3}\right)$. 1-Hexene was purified by distillation over sodium and stored over $3 \AA \AA$ molecular sieves under a nitrogen atmosphere. All alkyne and precatalyst stock solutions were stored under nitrogen and used immediately after preparation. Flash chromatography was carried out on untreated silica gel 60 from Sorbtech Technologies Inc. (230 - 400 mesh) under air pressure. Thin layer chromatography (TLC) was performed on glass-backed silica plates (F254, 250 micron thickness, EMD Millipore), visualized with UV light, phosphomolybdic acid, iodine, or potassium permanganate. IR kinetics were obtained using a ReactIR ${ }^{\mathrm{TM}} \mathrm{iC} 10$ equipped with a K4 conduit and a SiComp ${ }^{\mathrm{TM}}$ sensor $(2.5 \mathrm{~cm} \times 10 \mathrm{~cm})$ running $\mathrm{iC}^{\mathrm{TM}}$ IR software. UV-Vis kinetic were obtained using a Bio-Tek Instruments Uvikon XL UV/VIS spectrophotometer running LabPowerJr software. Preparative TLC was carried out using glass-backed silica plates (F254, $1 \mathrm{~mm}$ thickness) and visualized with UV light. ${ }^{1} \mathrm{H}$ NMR spectra were recorded at 300,400 , or $500 \mathrm{MHz}$ and ${ }^{13} \mathrm{C}$ NMR spectra were recorded at $75 \mathrm{MHz}$ using Varian Mercury 300, Inova 400, Inova 500 instruments. ${ }^{1} \mathrm{H}$ NMR chemical shifts are reported in ppm relative to the solvent used (chloroform-d ${ }^{1} \mathrm{H}$ : $7.26 \mathrm{ppm},{ }^{13} \mathrm{C}$ : $77 \mathrm{ppm}$ and benzene ${ }^{1} \mathrm{H}: 7.15 \mathrm{ppm},{ }^{13} \mathrm{C}: 128 \mathrm{ppm}$ ). Infrared spectra were recorded using a Perkin Elmer Spectrum Two FTIR-ATR or a Perkin Elmer Paragon 1000 (thin film). Elemental analyses were performed by Atlantic Microlabs, Inc. in Norcross, GA.

\section{B. Kinetic Procedures - Ene-yne Metathesis}

Ene-yne metathesis kinetics were tracked using a ReactIR ${ }^{\mathrm{TM}} \mathrm{iC} 10$ equipped with a $\mathrm{K} 4$ conduit and a SiComp ${ }^{\mathrm{TM}}$ sensor $(2.5 \mathrm{~cm} \times 10 \mathrm{~cm})$ running $\mathrm{iC}^{\mathrm{TM}} \mathrm{IR}$ software. The disappearance of alkyne was tracked using the $\mathrm{C}-\mathrm{H}$ stretch at $3310 \mathrm{~cm}^{-1}$ for terminal alkynes (1A, 1B, 1C) and the carbonyl absorbance at $1755 \mathrm{~cm}^{-1}$ for internal alkyne 15. Temperature control was achieved using a water bath regulated by a Haake C1 thermostat. Reactions were performed using a $50 \mathrm{~mL}$ oven-dried flask with an internally threaded glass adapter sealed with a PTFE bushing and Viton O-ring around the probe. The flask was equipped with a magnetic stirbar, sealed with a rubber septum and cooled under a nitrogen atmosphere. 
Reactions were carried out by transferring a desired amount of the alkyne stock solution and neat 1-hexene using gas tight syringes. The alkene/alkyne solution was then diluted to $2.96 \mathrm{~mL}$ with dry/purged toluene. The solution was then equilibrated at $25^{\circ} \mathrm{C}$ for 10 minutes under a nitrogen atmosphere. Then a $40 \mu \mathrm{L}$ volume of precatalyst stock solution was injected into the reaction flask. Consumption of alkyne was followed in situ by the decreasing IR absorbance at $3310 \mathrm{~cm}^{-1}$. All reactions were run in duplicate using the same stock solutions, additional runs were also performed using new stock solutions in order to asses reproducibility of the experiments. The slope of the line $\left(k_{\text {obs }}\right)$ is calculated with the error limits at the 95\% confidence interval using Microsoft Excel. For reactions that went to incomplete conversion with $1 \mathrm{~A},{ }^{1} \mathrm{H}$ NMR was used to analyze the mixture. Once the reaction solvent was removed, mesitylene ( 0.33 equiv) was added with $\mathrm{CDCl}_{3}$ and the product mixture was analyzed by ${ }^{1} \mathrm{H}$ NMR. Conversion was determined by ${ }^{1} \mathrm{H}$ NMR by integration of the product $2 \mathrm{~A}$ ( $E / Z$ mixture) at 5.34 and 5.20 ppm (singlets), the alkyne $1 \mathrm{~A}$ at $2.49 \mathrm{ppm}$ (s) versus mesitylene at $6.8 \mathrm{ppm}$ (s).

\section{Validation of in situ IR Method}

Gas chromatography was performed on a Shimadzu GC-17A using a capillary column (Agilent Technologies, Inc., $0.25 \mathrm{~mm} \times 30 \mathrm{~m}, 0.25$ micron, HP-5) with FID detection using a standard temperature program $\left(40{ }^{\circ} \mathrm{C}\right.$ for $4 \mathrm{~min}$; then $20^{\circ} \mathrm{C} / \mathrm{min}$ to 280 ${ }^{\circ} \mathrm{C}$ and held for 20 minutes (total time: $36 \mathrm{~min}$ ); detector and injector at $280{ }^{\circ} \mathrm{C}$ ). Calibration curves were obtained for 1C, 5-decene, and the diene product using dodecane as the internal standard.

An oven-dried, jacketed schlenk flask was equipped with a magnetic stirbar, sealed with a rubber septum and cooled under a nitrogen atmosphere. 1-Hexene (3.59 $\mathrm{mL}, 28.7 \mathrm{mmol}), 1 \mathrm{~A}$ (200 mg, $1.15 \mathrm{mmol})$, dodecane $(261 \mu \mathrm{L}, 1.15 \mathrm{mmol})$, and toluene $(10.4 \mathrm{~mL})$ were added to the flask and equilibrated at $25^{\circ} \mathrm{C}$ for 10 minutes. Ru1 was added $(91 \mu \mathrm{L}$ of a $15.8 \mathrm{mM}$ solution, $0.00144 \mathrm{mmol}$ ) and $1 \mathrm{~mL}$ aliquots were taken every $30 \mathrm{~s}$ and quenched by purging with carbon monoxide. ${ }^{4}$ The quenched samples were then passed through a 3-4 mm plug of silica gel with an additional $1 \mathrm{~mL}$ of dichloromethane. The diluted samples were then subjected to GC analysis. The resulting FID absorbances were used to calculate concentrations of the reactants and products at specific reaction times to generate a plot of concentration vs. time (Figure S1). The diene production rate is directly proportional to alkyne consumption. Alternatively, data generated using the ReactIR ${ }^{\mathrm{TM}}$ method for alkyne consumption can be used to generate diene concentration using this method: $[\mathbf{2 A}]_{t}=[1 \mathrm{~A}]_{0}-[\mathbf{1 A}]_{\mathrm{t}}$. 


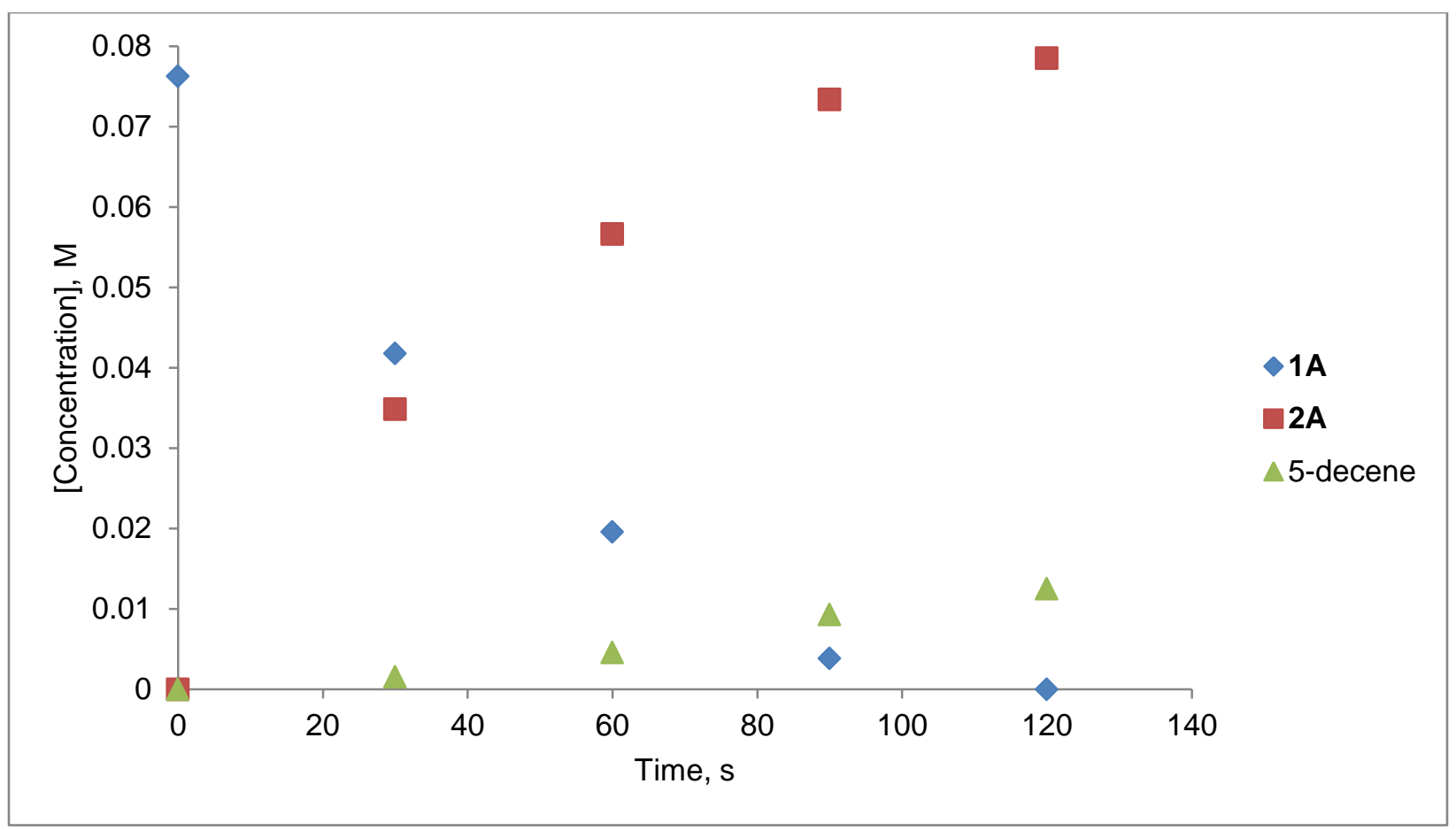

Figure S1. Gas Chromatography Conversion Study for Ene-yne Metathesis. Conditions: $0.08 \mathrm{M}$ 1A, $2 \mathrm{M}$ 1-hexene, $0.0001 \mathrm{M}$ Ru1, toluene, $25^{\circ} \mathrm{C}, 0.08 \mathrm{M}$ dodecane as internal standard.

The observance of 5-decene formation during the time period of the $\mathrm{GC}$ reaction led us to evaluate catalyst lifetime. After the alkyne consumption was complete ( 120 s) in Figure S1, no further 5-decene formation was observed indicating no active catalyst remains. A secondary study was performed to evaluate catalyst activity over a period of time in the absence of an alkyne. For a typical reaction at low 1-hexene concentration (0.5 - $1 \mathrm{M}$ ) incomplete alkyne consumption is observed (entries 1-6, Table S1) due to catalyst decomposition. In order to evaluate catalyst lifetime, a reaction was performed in the absence of alkyne (Figure S2). In this case, conversion to 5-decene was still observed after $1200 \mathrm{~s}$, or at least ten time longer than observed for ene-yne metathesis. Catalyst activity was found to be longer-lived for olefin metathesis conditions when compared to ene-yne metathesis conditions using identical catalyst and 1-hexene concentrations. 


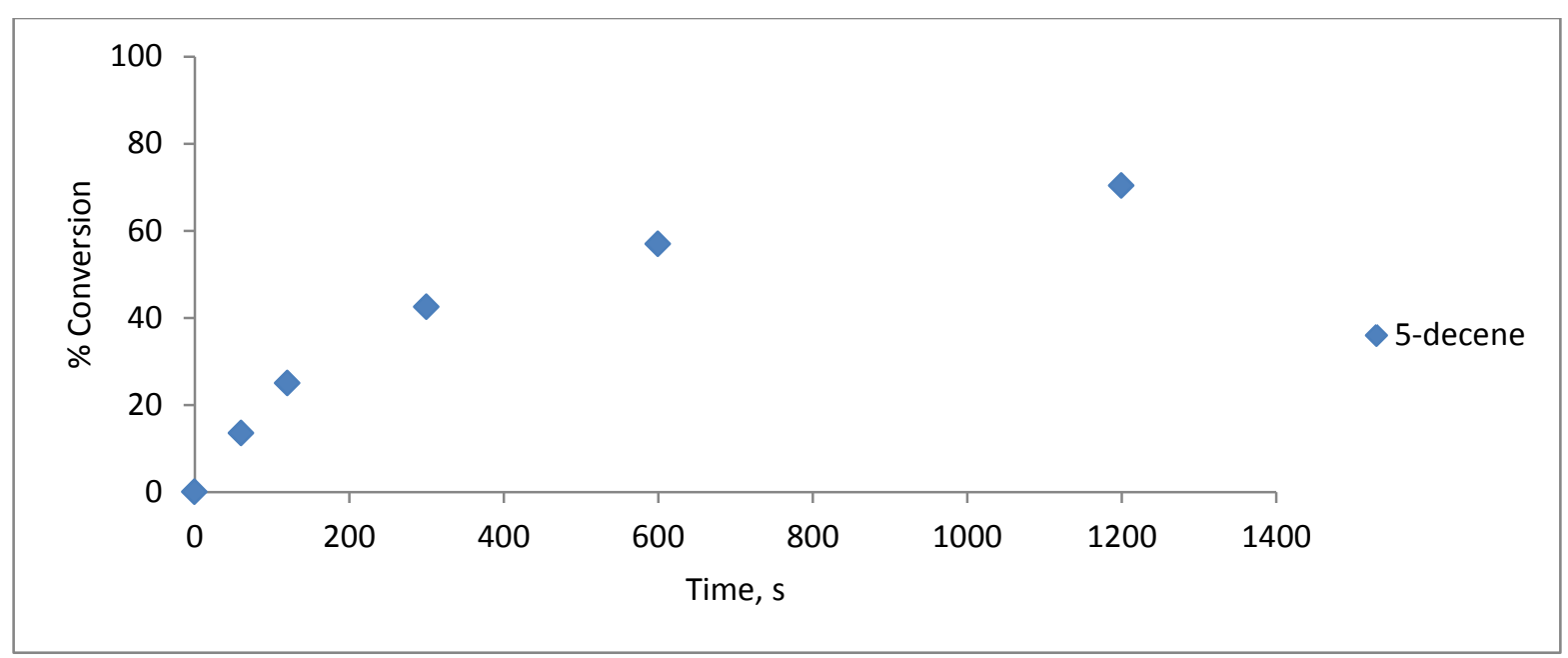

Figure S2. Gas Chromatography Conversion Study for Olefin Metathesis. Conditions: 1 M 1-hexene, $0.1 \mathrm{mM}$ Ru1, toluene, $25^{\circ} \mathrm{C}, 0.2 \mathrm{M}$ dodecane as internal standard.

\section{Order in Reactants and Precatalyst}

Data sets were obtained as absorbance vs. time from the $\mathrm{iC}^{\mathrm{TM}} \mathrm{IR}$ software and all kinetic treatments were carried out using Microsoft Excel. The data was normalized to zero absorbance at a time which corresponded with complete alkyne consumption. For reactions that did not go to completion, the data was normalized to an absorbance which reflected the amount of alkyne remaining after no further conversion (catalytic activity) was observed. The amount of alkyne remaining was determined independently using ${ }^{1} \mathrm{H}$ NMR of the crude reaction mixture with mesitylene as an internal standard. The resulting data were converted to concentration by dividing absorbances by an effective extinction coefficient determined by dividing the absorbance at time $=0$ by the initial alkyne concentration. A representative plot is shown in Figure S3; the slope of the line gives a pseudo-zero order rate constant, $k_{o b s}$, for every reaction. In these reactions, $k_{o b s}=$ rate and each have units of $\mathrm{M} \mathrm{s}^{-1}$. In each case, the plot of concentration vs. time was linear, demonstrating a rate law that is zero-order in alkyne. For reactions that did not go to completion due to catalyst decomposition, initial rates were used for a region which maintained linearity. 


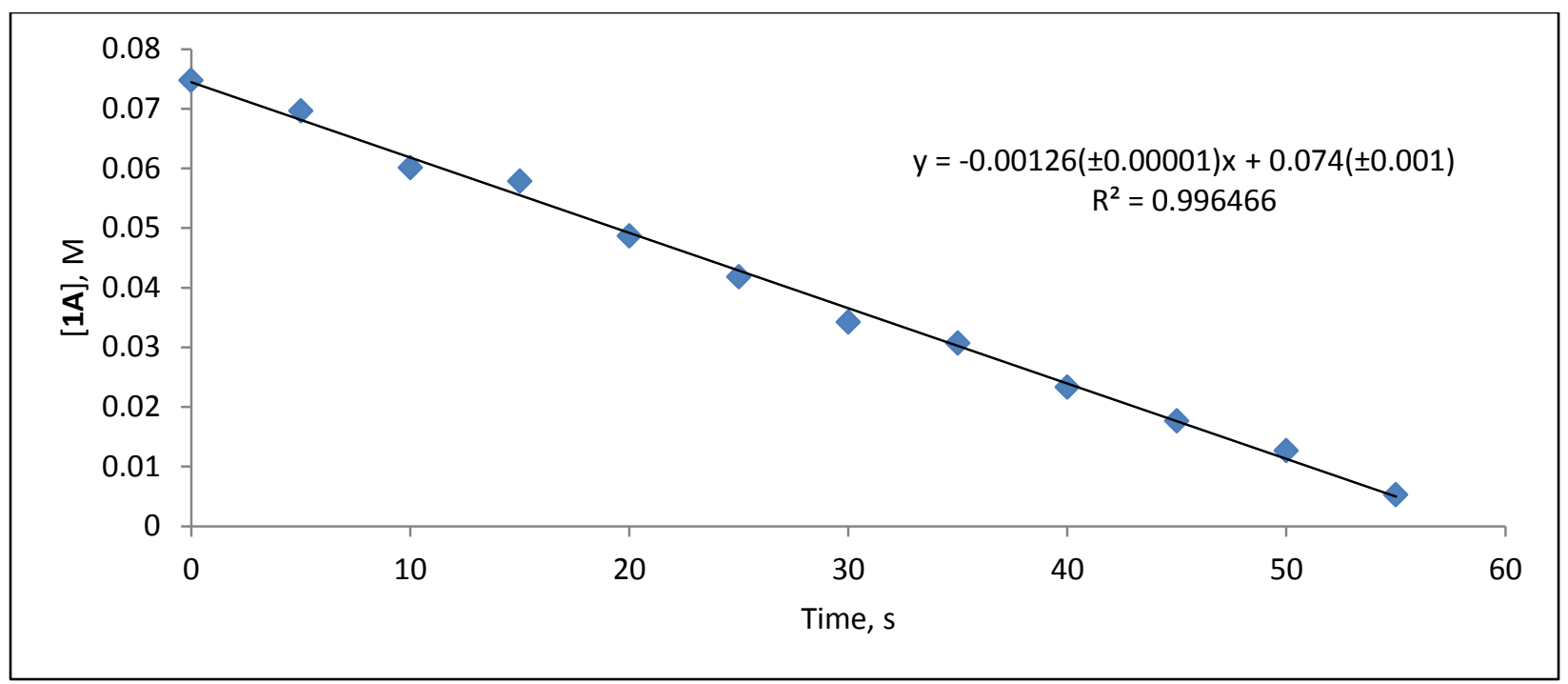

Figure S3. Representative Plot of 1-Hexene Metathesis. $k_{o b s}$ was found to be 0.00126 $\mathrm{M} \mathrm{s}^{-1}$. Conditions: $0.08 \mathrm{M} \mathrm{1A}, 3 \mathrm{M} 1$-hexene, $0.0001 \mathrm{M}$ Ru1, toluene, $25^{\circ} \mathrm{C}$.

Data were generated using toluene and 1,2-dichloroethane as solvents. Catalyst decomposition in toluene had a pronounced effect on the observed rate due to such low catalyst loadings $(0.1 \mathrm{mM}$ Ru1) being employed in the ene-yne metathesis. In order to overcome this, 1,2-dichloroethane was employed with $3 \mathrm{mM}$ Ru1 which also demonstrated zero order dependence in alkyne. Plots of $\ln \left(k_{o b s}\right)$ vs. $\operatorname{In}$ [catalyst] and $\ln \left(k_{o b s}\right)$ vs. In[alkene] exhibited slopes of 1 , giving an equation rate $=k_{E Y M}$ [Ru1] ${ }^{1}[1-$ hexene $]^{1}[1 \mathrm{~A}]^{0}$. The second order rate constant, $k_{E Y M}$, was found from the rate law: rate $=k_{o b s}$, where $k_{o b s}=k_{E Y M}[1 \text {-hexene }]^{1}[\mathbf{R u} 1]^{1}$. Values of $k_{E Y M}$ for 1 -hexene-1A metathesis are given in Table $\mathrm{S} 1$. 
Table S1. Kinetic Data for 1-Hexene-Alkyne (1A) Metathesis in Toluene at $25^{\circ} \mathrm{C}$.

\begin{tabular}{|c|c|c|c|c|c|}
\hline Entry & [Ru1], M & [1-hexene], M & {$[1 \mathrm{~A}], \mathrm{M}$} & $k_{o b s}, \mathrm{M} \mathrm{s}^{-1}$ & $k_{E Y M}, \mathrm{M}^{-1} \mathrm{~s}^{-1}$ \\
\hline $1^{\mathrm{a}}$ & 0.00010 & 0.5 & 0.08 & 0.000144 & 2.9 \\
\hline $2^{\mathrm{a}}$ & 0.00010 & 0.5 & 0.08 & 0.000188 & 3.8 \\
\hline $3^{\mathrm{a}}$ & 0.00010 & 0.5 & 0.08 & 0.000268 & 5.4 \\
\hline $4^{\mathrm{a}}$ & 0.00010 & 1.0 & 0.08 & 0.000330 & 3.3 \\
\hline $5^{a}$ & 0.00010 & 1.0 & 0.08 & 0.000401 & 4.0 \\
\hline $6^{a}$ & 0.00010 & 1.0 & 0.08 & 0.000338 & 3.4 \\
\hline 7 & 0.00010 & 1.5 & 0.08 & 0.000533 & 3.6 \\
\hline 8 & 0.00010 & 1.5 & 0.08 & 0.000503 & 3.3 \\
\hline 9 & 0.00010 & 1.5 & 0.08 & 0.000519 & 3.5 \\
\hline 10 & 0.00010 & 2.0 & 0.08 & 0.000702 & 3.5 \\
\hline 11 & 0.00010 & 2.0 & 0.08 & 0.000744 & 3.7 \\
\hline 12 & 0.00010 & 2.0 & 0.08 & 0.000739 & 3.7 \\
\hline 13 & 0.00010 & 2.0 & 0.08 & 0.000664 & 3.3 \\
\hline 14 & 0.00010 & 2.0 & 0.08 & 0.000880 & 4.4 \\
\hline 15 & 0.00010 & 2.0 & 0.08 & 0.000936 & 4.7 \\
\hline 16 & 0.00010 & 2.5 & 0.08 & 0.000988 & 4.0 \\
\hline 17 & 0.00010 & 2.5 & 0.08 & 0.001070 & 4.3 \\
\hline 18 & 0.00010 & 2.5 & 0.08 & 0.000847 & 3.4 \\
\hline 19 & 0.00010 & 3.0 & 0.08 & 0.001260 & 4.2 \\
\hline 20 & 0.00010 & 3.0 & 0.08 & 0.001270 & 4.2 \\
\hline 21 & 0.00010 & 3.0 & 0.08 & 0.000901 & 3.0 \\
\hline 22 & 0.00010 & 3.0 & 0.08 & 0.001350 & 4.5 \\
\hline 23 & 0.00010 & 3.0 & 0.08 & 0.001140 & 3.8 \\
\hline 24 & 0.00010 & 3.5 & 0.08 & 0.001480 & 4.2 \\
\hline 25 & 0.00010 & 3.5 & 0.08 & 0.001560 & 4.5 \\
\hline 26 & 0.00010 & 3.5 & 0.08 & 0.000942 & 2.7 \\
\hline 27 & 0.00010 & 4.0 & 0.08 & 0.001660 & 4.1 \\
\hline 28 & 0.00010 & 4.0 & 0.08 & 0.002000 & 5.2 \\
\hline 29 & 0.00010 & 4.0 & 0.08 & 0.001420 & 3.6 \\
\hline 30 & 0.0010 & 0.5 & 0.08 & 0.001920 & 3.8 \\
\hline 31 & 0.0010 & 0.5 & 0.08 & 0.001700 & 3.4 \\
\hline 32 & 0.00075 & 0.5 & 0.08 & 0.001680 & 4.5 \\
\hline 33 & 0.00075 & 0.5 & 0.08 & 0.001430 & 3.8 \\
\hline 34 & 0.0005 & 0.5 & 0.08 & 0.001020 & 4.1 \\
\hline 35 & 0.0005 & 0.5 & 0.08 & 0.001040 & 4.1 \\
\hline 36 & 0.00025 & 0.5 & 0.08 & 0.000492 & 3.9 \\
\hline 37 & 0.00025 & 0.5 & 0.08 & 0.000579 & 4.6 \\
\hline \multicolumn{5}{|c|}{$\begin{array}{l}{ }^{a} \text { Reactions did not go to completion, \% conversion was } \\
\text { determined by }{ }^{1} \mathrm{H} \text { NMR using mesitylene as an internal } \\
\text { standard and initial rates were used where linear } \\
\text { disappearance was observed. Error for the measurements is } \\
5 \% \text {. }\end{array}$} & $\begin{array}{c}\text { Average } \\
\text { value }= \\
3.9 \pm 0.6\end{array}$ \\
\hline
\end{tabular}


Precatalyst Dependence in Toluene

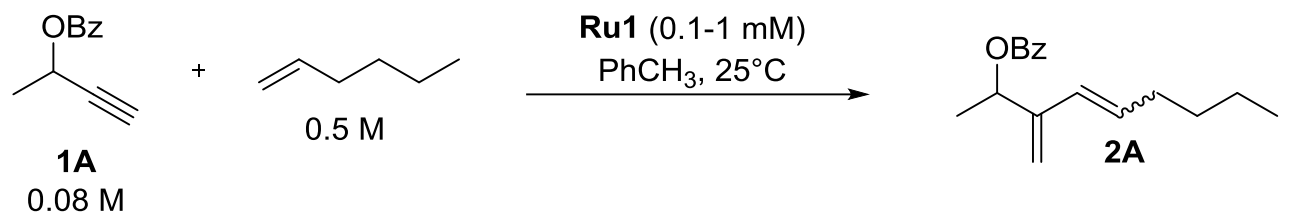

Plots in Figure S4 were obtained from data presented in Table S1, using the conditions outlined in equation 1. Plotting $k_{o b s}$ vs. [Ru1] shows a linear dependence on precatalyst with a y-intercept of $0 . \ln \left(k_{\text {obs }}\right)$ vs. $\ln [\mathbf{R u 1}$ ] gives a line with the slope of 0.97 indicating a first order dependence on the precatalyst Ru1.

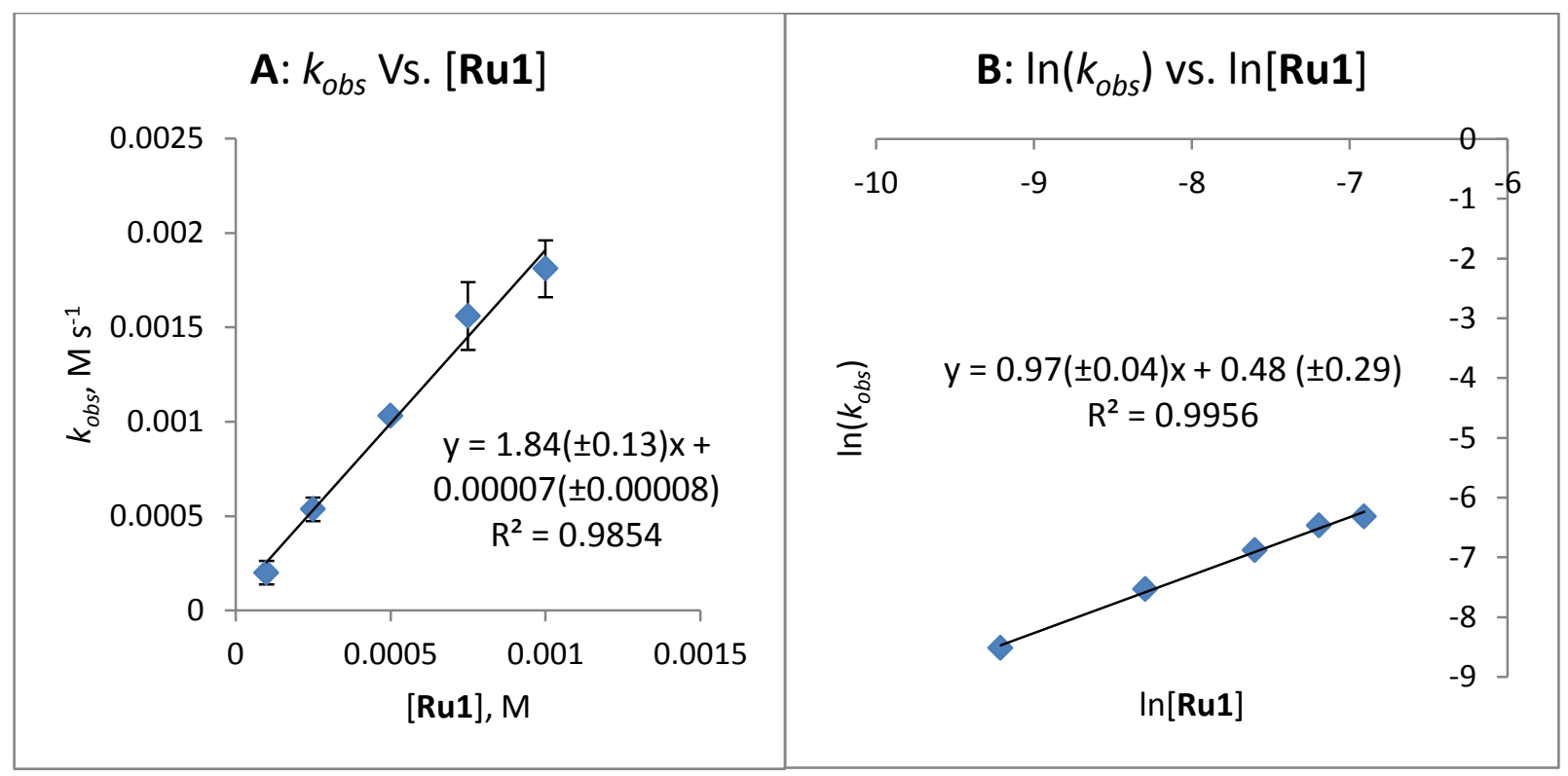

Figure S4. Determination of Catalyst Dependency. Conditions: $0.08 \mathrm{M} 1 \mathrm{~A}, 0.5 \mathrm{M} 1-$ hexene, $0.001-0.0001 \mathrm{M}$ Ru1, toluene, $25^{\circ} \mathrm{C}$. A: $k_{\text {obs }}$ vs. [Ru1], linear increase in rate with increasing [catalyst], y-intercept $=0.00007$; B: First order dependence on [Ru1] determined from slope of $\ln \left(k_{\text {obs }}\right)$ vs. $\operatorname{In}[$ Ru1] plot, slope $=0.97$. 
Alkene Dependence in Toluene

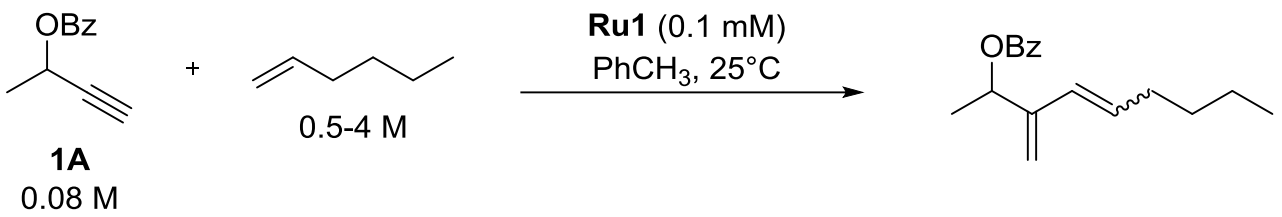

Plots in Figure S5 were obtained from data presented in Table S1, using the conditions outlined in equation 2. Plotting $k_{o b s}$ vs. [1-hexene] shows a linear dependence on 1 -hexene concentration with a y-intercept of $0 . \ln \left(k_{o b s}\right)$ vs. $\ln [1$-hexene] gives a line with the slope of 1.03 , indicating a first order dependence on the [1-hexene].

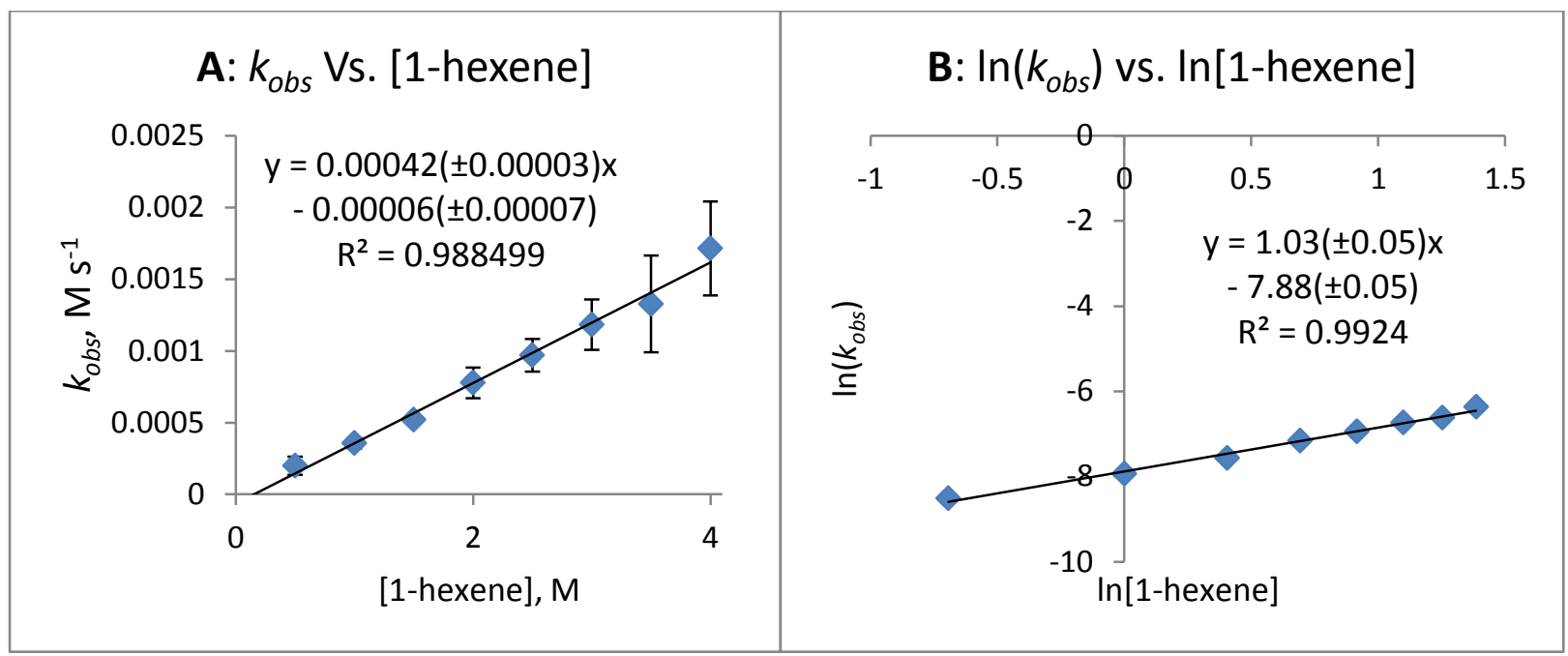

Figure S5. Determination of Alkene Dependency. Conditions: $0.08 \mathrm{M} \mathrm{1A}, 0.5-4 \mathrm{M} 1$ hexene, $0.0001 \mathrm{M}$ Ru1, toluene, $25^{\circ} \mathrm{C}$. A: $k_{\text {obs }}$ vs. [1-hexene], linear increase in rate with increasing [1-hexene] and no saturation was observed, y-intercept $=0.00006$; $\mathbf{B}$ : First order dependence on [1-hexene] determined from slope of $\ln \left(k_{o b s}\right)$ vs. $\ln [1$-hexene] plot, slope $=1.03$. 
Solvent Effects

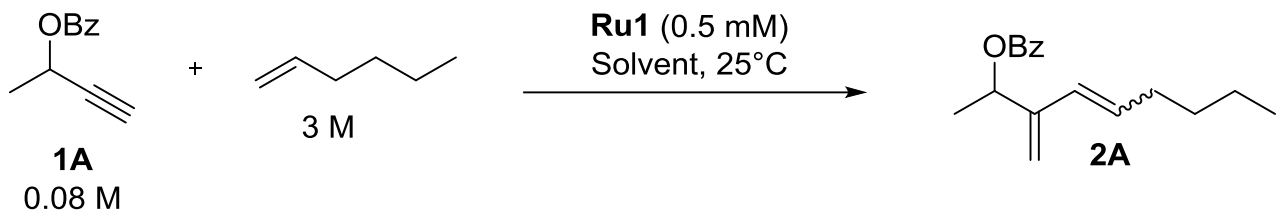

When employing different solvents for ene-yne metathesis of 1A-1-hexene with Ru1, a pronounced solvent effect was observed. Using identical concentrations for alkene, alkyne, and precatalyst, the rate for toluene $\left(k_{\text {obs }}=\geq 0.0046 \mathrm{M} \mathrm{s}^{-1}\right)$ was found to be at least 6 times faster than 1,2-dichloroethane $\left(k_{o b s}=0.00064 \mathrm{M} \mathrm{s}^{-1}\right)$. Due to the very fast reaction in toluene, only two data points were collected with IR scans taken every $15 \mathrm{~s}$ and the slope of the line represents a lower limit for the rate of the reaction. The linear slope observed for 1,2-dichloroethane also showed a zero-order dependence on alkyne which is consistent with what was observed for toluene.

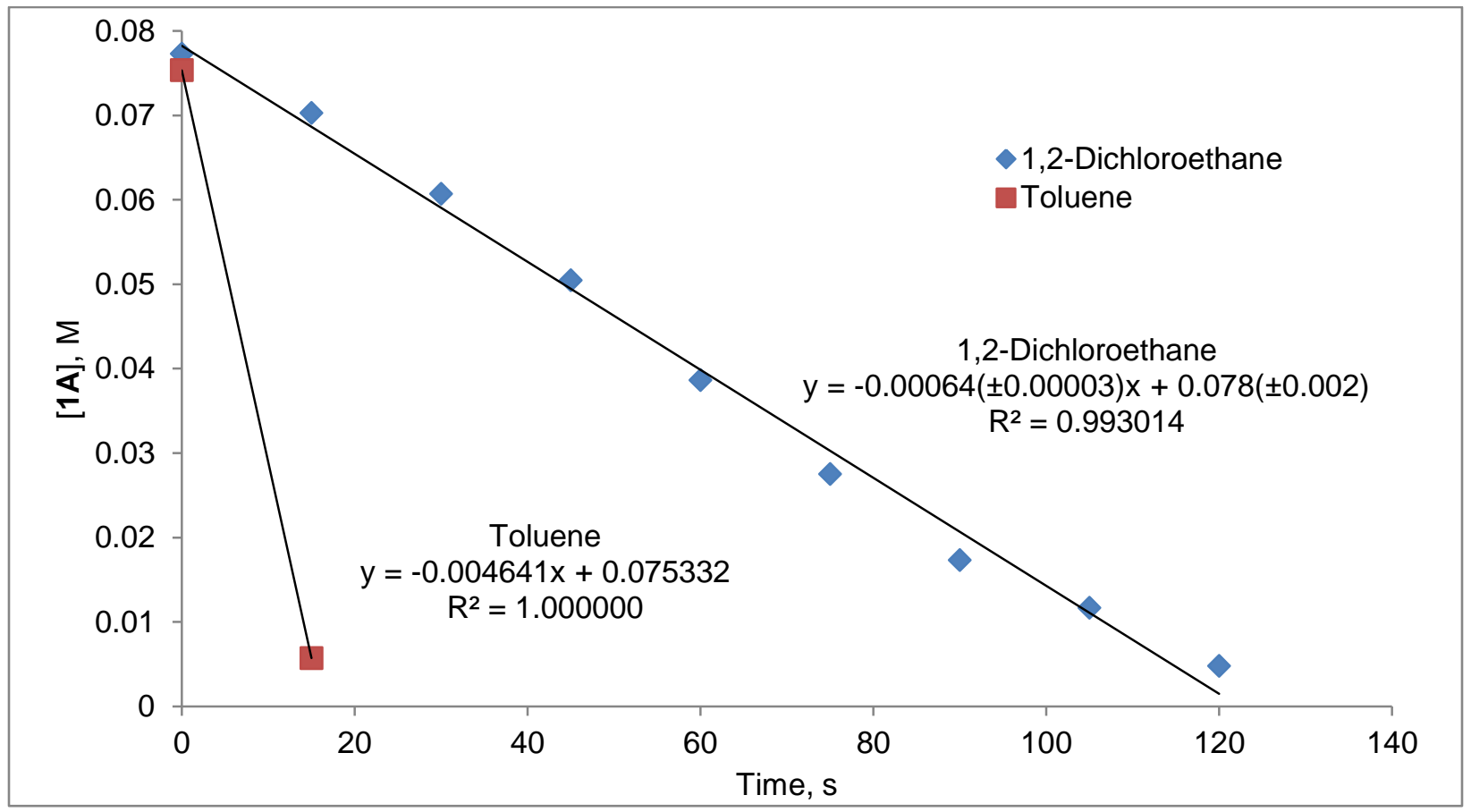

Figure S6. Solvent Effects. Identical conditions were employed using 1,2dichloroethane and toluene as solvents to evaluate their effect of the rate of ene-yne metathesis using Ru1. Conditions: 0.08 M 1A, 0.5 mM Ru1, 3 M 1-hexene, toluene ( $k_{o b s}$ $=\geq 0.0046 \mathrm{M} \mathrm{s}^{-1}$.) or 1,2 -dichloroethane $\left(k_{o b s}=0.00064 \mathrm{M} \mathrm{s}^{-1}\right.$.), $25^{\circ} \mathrm{C}$. 
Precatalyst Dependency in 1,2-Dichloroethane

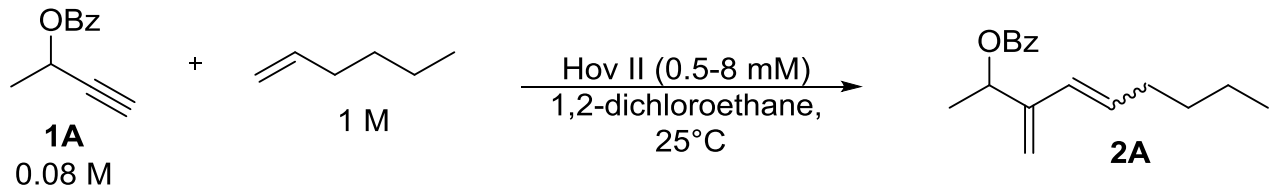

Further studies were conducted to establish precatalyst order in 1,2dichloroethane (Table S2). When the data was plotted as $k_{\text {obs }}$ vs. [Ru1] (Figure S7) it showed a linear dependence on concentration with a y-intercept of 0 . The plot of $\ln \left(k_{o b s}\right)$ vs. In[Ru1] gave a line with the slope of 1.04 which indicated a first-order dependence on [Ru1].

Table S2. Data Summary for Precatalyst Dependency in 1,2-Dichloroethane.

\begin{tabular}{|c|c|c|c|c|}
\hline Entry & [Ru1], M & {$[1 \mathrm{~A}], \mathrm{M}$} & [1-hexene], M & $k_{o b s}, \mathrm{M} \mathrm{s}^{-1}$ \\
\hline 1 & 0.0080 & 0.08 & 1 & 0.00201 \\
\hline 2 & 0.0040 & 0.08 & 1 & 0.00109 \\
\hline 3 & 0.0020 & 0.08 & 1 & 0.000536 \\
\hline 4 & 0.0010 & 0.08 & 1 & 0.000246 \\
\hline 5 & 0.0005 & 0.08 & 1 & 0.000114 \\
\hline
\end{tabular}

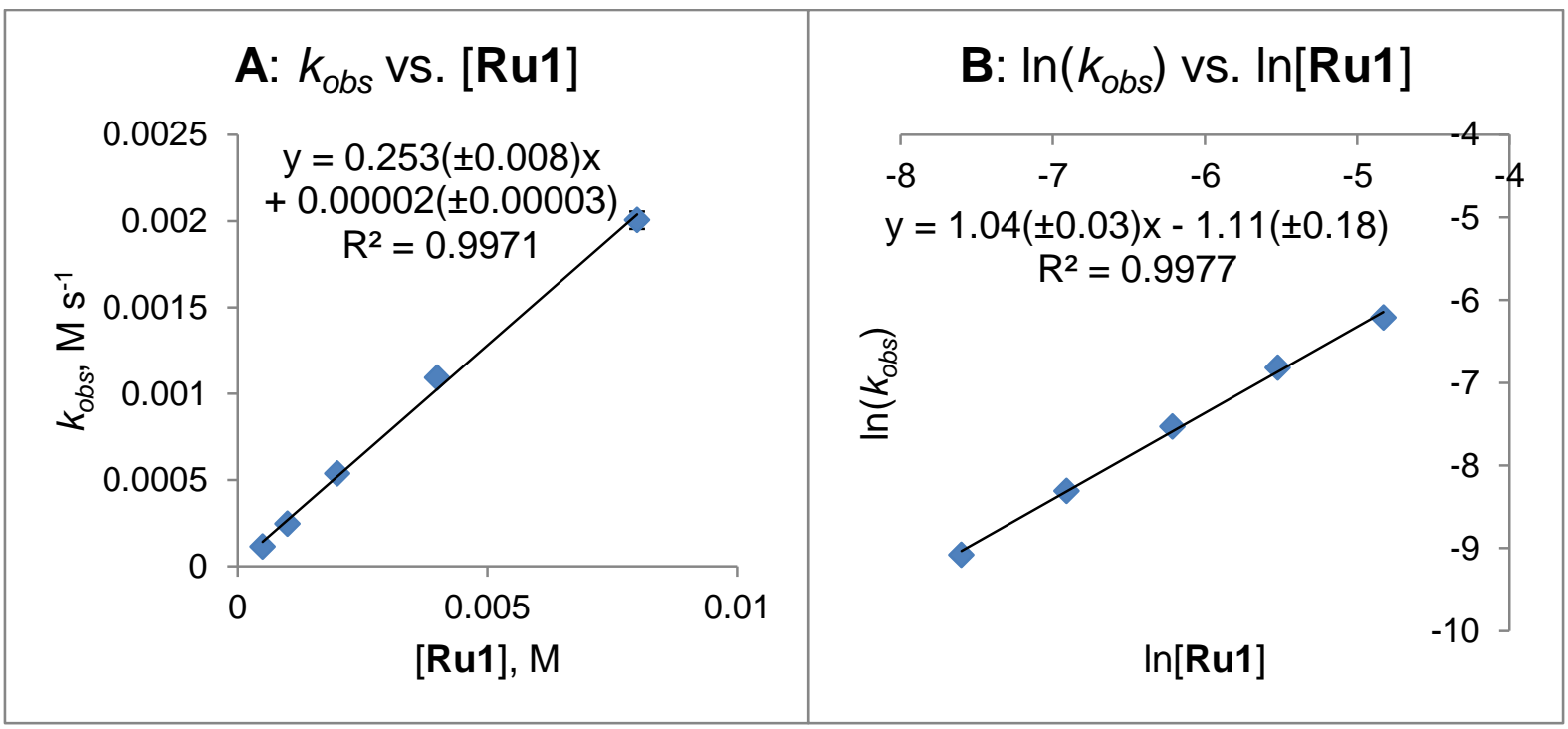

Figure S7. Determining Precatalyst Dependency in 1,2-Dichloroethane. Conditions: $0.08 \mathrm{M}$ 1A, $1 \mathrm{M}$ 1-hexene, $0.0005-0.008 \mathrm{M}$ Ru1, 1,2-Dichloroethane, $25^{\circ} \mathrm{C}$. A: $k_{o b s}$ vs. [Ru1], linear increase in rate with increasing [catalyst], $y$-intercept $=0.00002$; $\mathbf{B}$ : First 
order dependence on [Ru1] determined from $\ln \left(k_{o b s}\right)$ vs. $\operatorname{In}[\mathbf{R u} 1]$ plot with a slope of 1.04 .

Alkene Dependency in 1,2-Dichloroethane
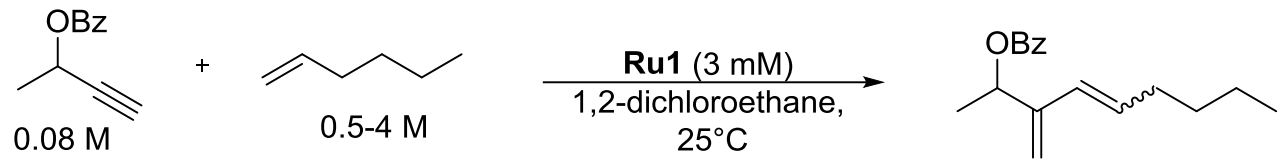

Alkene dependency was then established for conditions outlined in equation 5. The data in Table S3 was plotted as $k_{o b s}$ vs. [1-hexene] and showed no saturation kinetics in addition to a y-intercept close to 0 (Figure S8). When plotted as $\ln \left(k_{\text {obs }}\right)$ vs. In[1-hexene] the slope of the line was 1.25 indicating near first-order dependency in [1hexene] .

Table S3. Rates for Alkene Dependency Study.

\begin{tabular}{|c|c|c|c|c|}
\hline Entry & [Ru1], $\mathrm{M}$ & {$[\mathbf{1 A}], \mathrm{M}$} & {$[1$-hexene], $\mathrm{M}$} & $k_{\text {obs }}, \mathrm{M} \mathrm{s}^{-1}$ \\
\hline 1 & 0.003 & 0.08 & 0.7 & 0.00055 \\
\hline 2 & 0.003 & 0.08 & 1.0 & 0.00082 \\
\hline 3 & 0.003 & 0.08 & 1.3 & 0.00106 \\
\hline 4 & 0.003 & 0.08 & 1.8 & 0.00134 \\
\hline 5 & 0.003 & 0.08 & 2.0 & 0.00147 \\
\hline 6 & 0.003 & 0.08 & 2.5 & 0.00260 \\
\hline 7 & 0.003 & 0.08 & 3.0 & 0.00389 \\
\hline 8 & 0.003 & 0.08 & 4.0 & 0.00445 \\
\hline
\end{tabular}

Conditions: $0.08 \mathrm{M} 1 \mathrm{~A}, 0.7-4 \mathrm{M}$ 1-hexene, $0.003 \mathrm{M}$ Ru1, toluene, $25^{\circ} \mathrm{C}$. Error for the measurements is $5 \%$. 


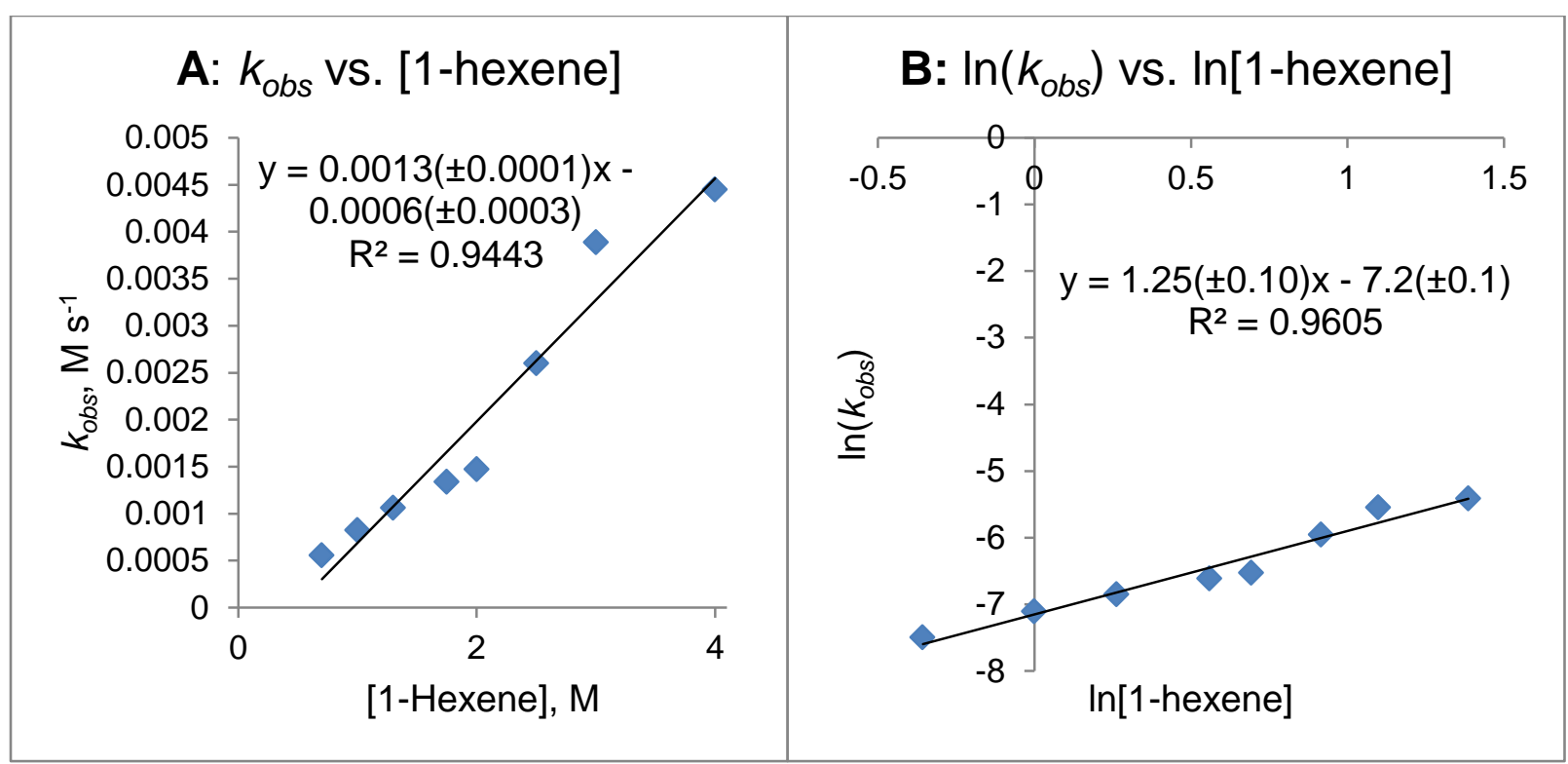

Figure S8. Determination of Alkene Dependency. Conditions: 0.08 M 1A, 0.7-4 M 1hexene, $0.003 \mathrm{M}$ Ru1, 1,2-Dichloroethane, $25^{\circ} \mathrm{C}$. A: $k_{\text {obs }}$ vs. [1-hexene] showed no saturation and a linear increase in rate with higher [1-hexene] concentration, $y$-intercept $=0.0006 ; \mathbf{B}: \ln \left(k_{o b s}\right)$ vs. $\ln [1$-hexene] displayed first order dependency, slope = 1.25. 
Alkyne Dependency in 1,2-Dichloroethane

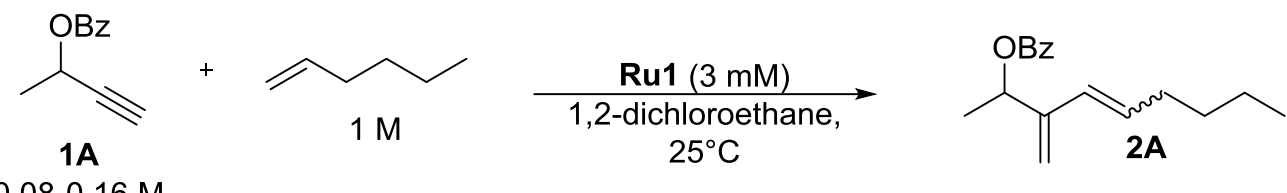

Verification of the observed zero-order dependence on alkyne was confirmed by an [alkyne] doubling experiment (Table S4, Figure S9). Identical rates were obtained at $0.08 \mathrm{M}[1 \mathrm{~A}]\left(k_{o b s}=0.00246 \mathrm{M} \mathrm{s}^{-1}\right)$ and $0.16 \mathrm{M}[1 \mathrm{~A}]\left(k_{o b s}=0.00253 \mathrm{M} \mathrm{s}^{-1}\right)$ using $1 \mathrm{M} \mathrm{1-}$ hexene and $3 \mathrm{mM}$ [Ru1].

Table S4. Data Summary for Alkyne Dependency in 1,2-Dichloroethane.

\begin{tabular}{|c|c|c|c|c|}
\hline [1-hexene], M & {$[$ Ru1], M } & {$[\mathbf{1 A}], \mathrm{M}$} & {$[1$-hexene], M } & $k_{\text {obs }}, \mathrm{M} \mathrm{s}^{-1}$ \\
\hline 2 & 0.003 & 0.08 & 1.0 & 0.00234 \\
\hline 2 & 0.003 & 0.16 & 1.0 & 0.00248 \\
\hline
\end{tabular}

Conditions: 0.08-0.16 M 1A, 2 M 1-hexene, 0.003 M Ru1, 1,2-Dichloroethane, 25

${ }^{\circ} \mathrm{C}$. Error for the measurements is $5 \%$.

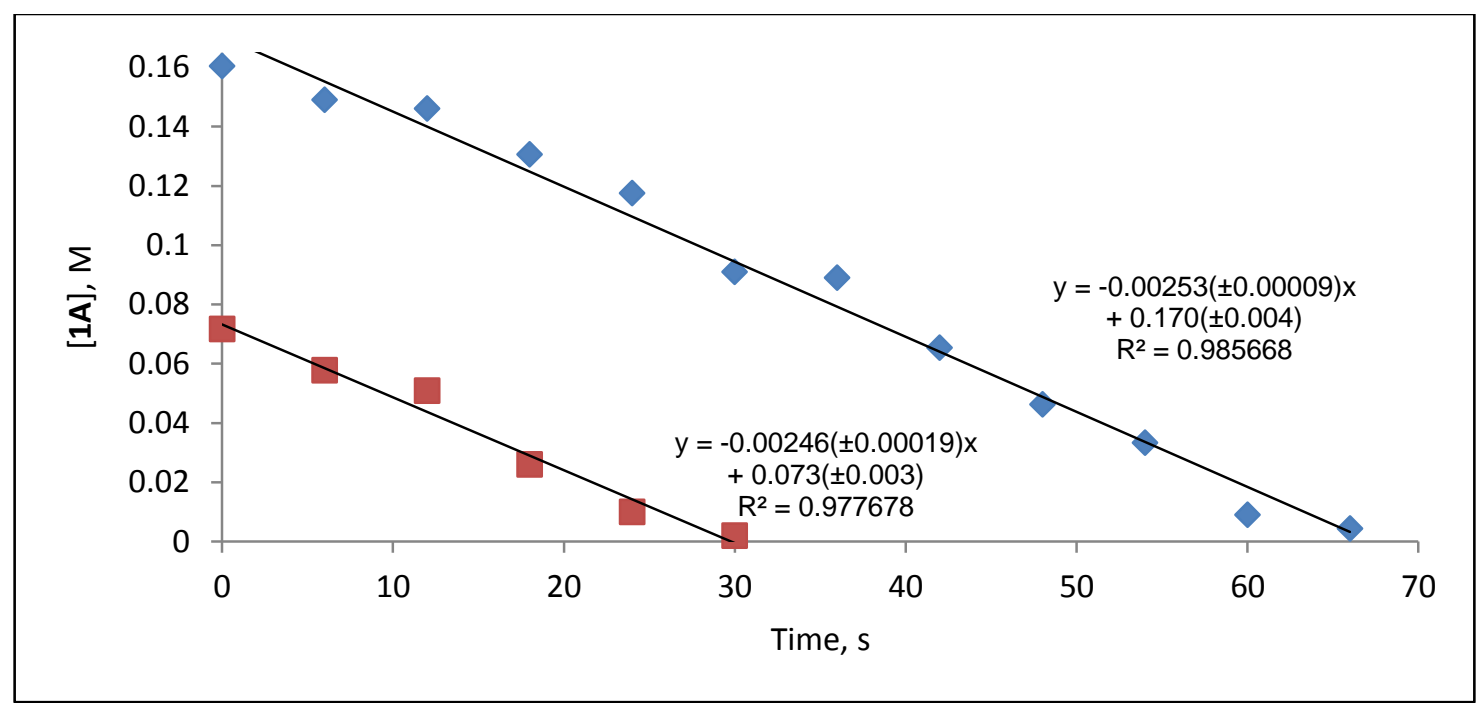

Figure 59. Representative Plot for Determining Alkyne Dependency in 1,2Dichloroethane. Conditions: 0.08-0.16 M 1A, 2 M 1-hexene, 0.003 M Ru1, 1,2Dichloroethane, $25^{\circ} \mathrm{C}$. Single runs displayed. 


\section{E. Dual Spectroscopic Measurements}

Precatalyst initiation was tracked using a Bio-Tek Instruments Uvikon XL UV-Vis spectrophotometer running LabPowerJr software. Precatalyst disappearance was followed at $377 \mathrm{~nm} .{ }^{5}$ Glass cuvettes $(3.5 \mathrm{~mL})$ were dried using a stream of nitrogen gas prior to use, air-free reactions were achieved by sealing the cuvette with a rubber septum under a balloon atmosphere of argon. Temperature control was achieved using a Fisher Scientific Isotemp refrigerated circulator (model 910). It is important to note that the overlays of precatalyst initiation and ene-yne metathesis (Figures S10-13) are of separate runs using different stock solutions under identical conditions.

Reactions were carried out by transferring a desired amount of the Ru1 stock solution and toluene with gas tight syringes to the cuvette. The solution was then equilibrated at $25{ }^{\circ} \mathrm{C}$ for 10 minutes under an argon atmosphere. Then a premixed solution of alkyne and alkene under equilibration at $25{ }^{\circ} \mathrm{C}$ was injected into the reaction flask (total volume $=3 \mathrm{~mL}$ ). Consumption of precatalyst was followed in situ by the decreasing UV-Vis absorbance at $377 \mathrm{~nm}$. All reactions were run in duplicate using the same stock solutions.

Data sets were graphed as absorbance vs. time plots from the LabPowerJr software and all kinetic treatments were carried out using Microsoft Excel. The data was normalized to zero absorbance at a time which corresponded to complete precatalyst consumption. The data sets were converted to concentration by dividing absorbances by an effective extinction coefficient determined by dividing the absorbance at time $=0$ by the initial precatalyst concentration. The data was then plotted with data from the React $R^{T M}$ on a separate $y$-axis. Data displayed in Figure S10-13 is the initial rate based on the slope of the line for the first $25 \mathrm{~s}$ of linear disappearance of precatalyst. Data reported in Table S4 and S5 was obtained by converting the plots to catalyst concentration using Beer's law, then plotting $\ln \left[\right.$ Ru1] vs. time where the slope $=-k$ in $s^{-1}$. 


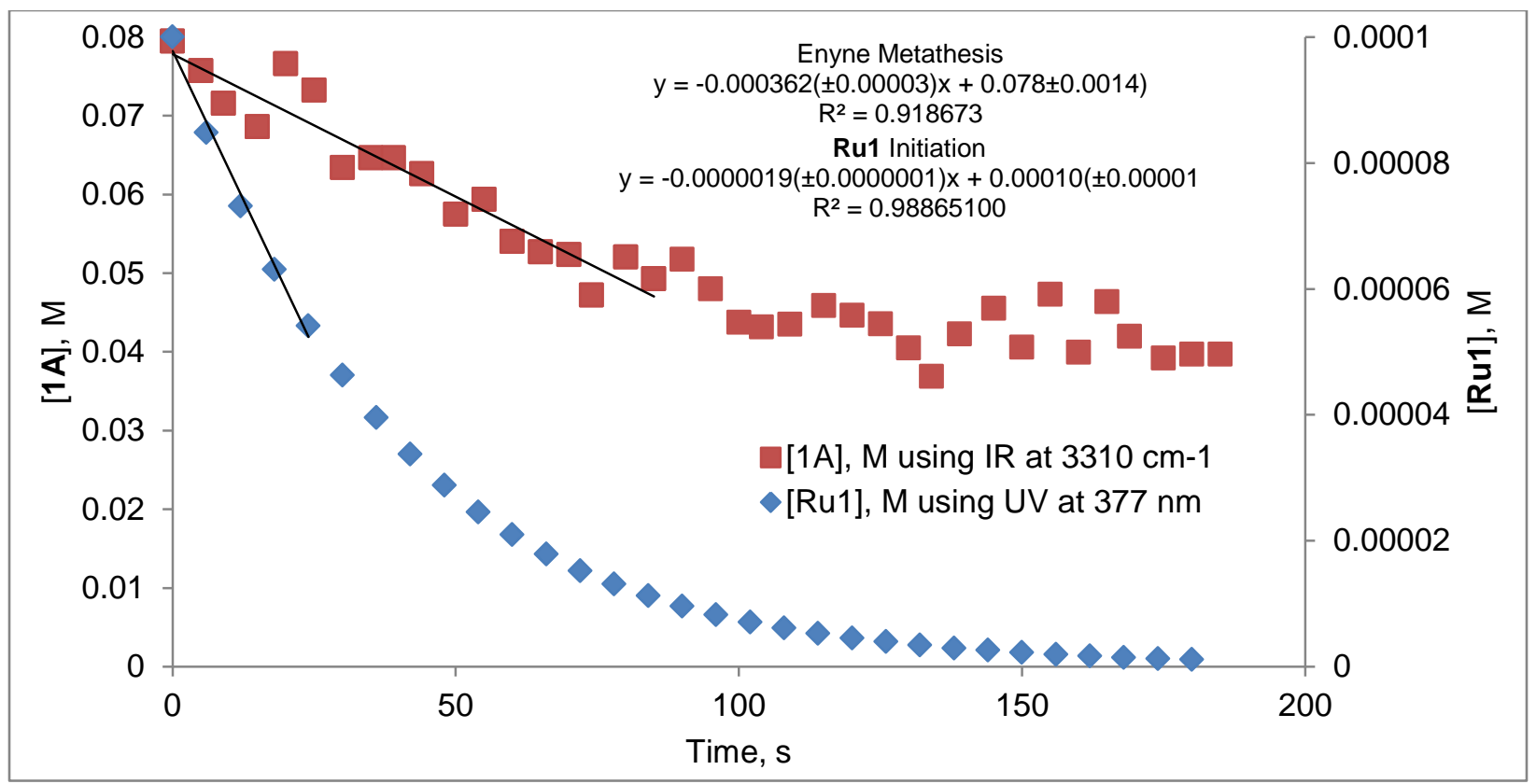

Figure S10. ReactIR ${ }^{\mathrm{TM}}$ and UV-Vis Overlay. Conditions: $0.08 \mathrm{M} 1 \mathrm{~A}, 1 \mathrm{M}$ 1-hexene, $0.0001 \mathrm{M}$ Ru1, toluene, $25^{\circ} \mathrm{C}$. For alkyne consumption $k_{\text {obs }}=0.000362 \mathrm{M} \mathrm{s}^{-1}$ (IR) with incomplete consumption confirmed by NMR analysis and for precatalyst the initial $k_{o b s}$ was determined to be $0.019 \mathrm{~s}^{-1}$ (UV-Vis). Each $k_{o b s}$ was estimated based on initial rates.

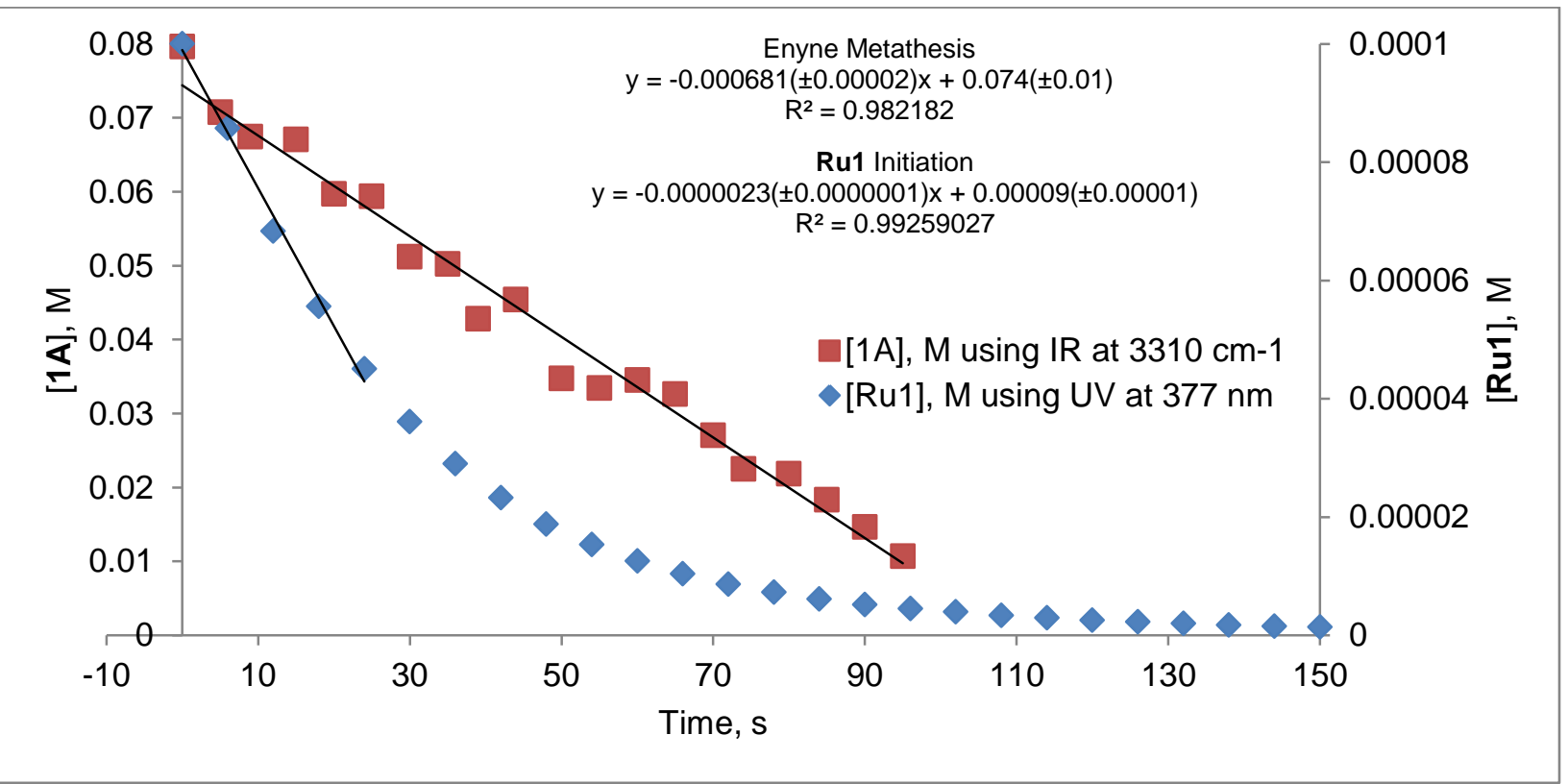

Figure S11. ReactIR ${ }^{T M}$ and UV-Vis Overlay. Conditions: $0.08 \mathrm{M}$ 1A, 2 M 1-hexene, $0.0001 \mathrm{M}$ Ru1, toluene, $25^{\circ} \mathrm{C}$. For alkyne consumption $k_{o b s}=0.000681 \mathrm{M} \mathrm{s}^{-1}$ (IR) and for precatalyst the $k_{\text {obs }}$ was determined using initial rates to be $0.023 \mathrm{~s}^{-1}$ (UV-Vis). 


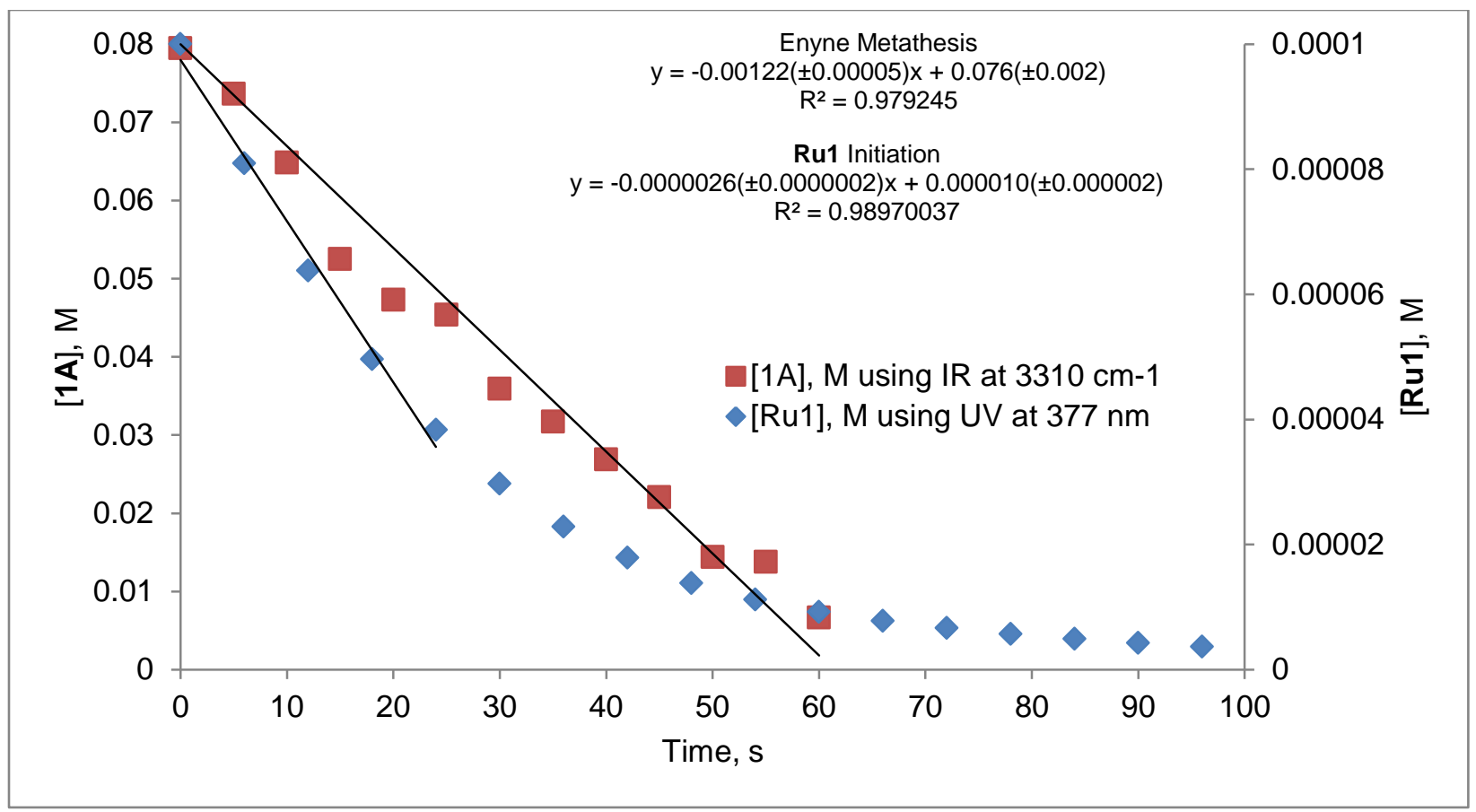

Figure S12. ReactIR ${ }^{\mathrm{TM}}$ and UV-Vis Overlay. Conditions: $0.08 \mathrm{M} 1 \mathrm{~A}, 3 \mathrm{M}$ 1-hexene, $0.0001 \mathrm{M}$ Ru1, toluene, $25^{\circ} \mathrm{C}$. For alkyne consumption $k_{o b s}=0.00122 \mathrm{M} \mathrm{s}^{-1}(\mathrm{IR})$ and for precatalyst the initial $k_{o b s}$ was determined using initial rates to be $0.026 \mathrm{~s}^{-1}$ (UV-Vis).

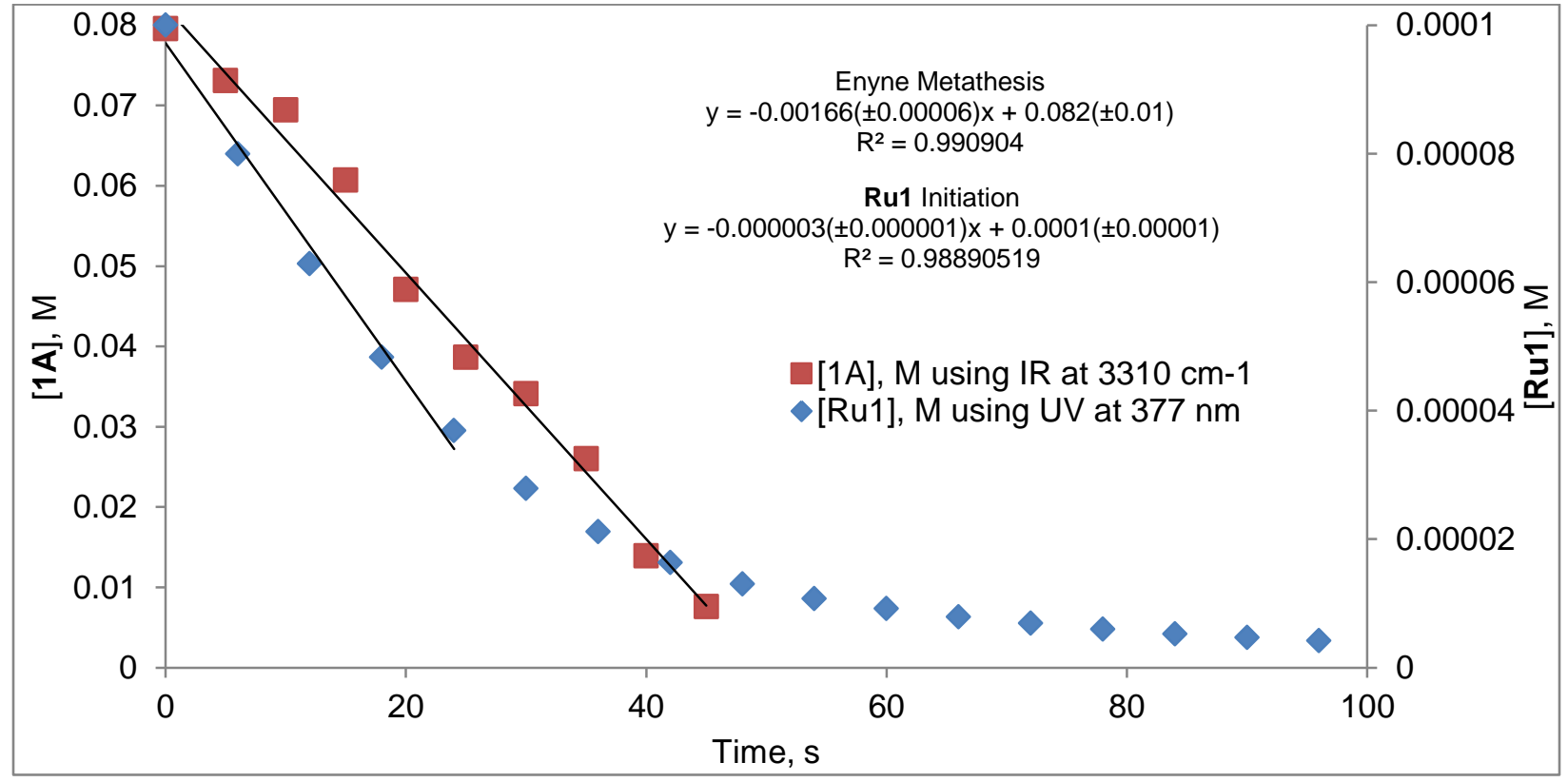

Figure S13. ReactIR ${ }^{\mathrm{TM}}$ and UV-Vis Overlay. Conditions: $0.08 \mathrm{M}$ 1A, $4 \mathrm{M}$ 1-hexene, $0.0001 \mathrm{M}$ Ru1, toluene, $25^{\circ} \mathrm{C}$. For alkyne consumption $k_{\text {obs }}=0.000681 \mathrm{M} \mathrm{s}^{-1}$ (IR) and for precatalyst the initial $k_{o b s}$ was determined using initial rates to be $0.03 \mathrm{~s}^{-1}$ (UV-Vis). 


\section{F. Alkyne Variation}

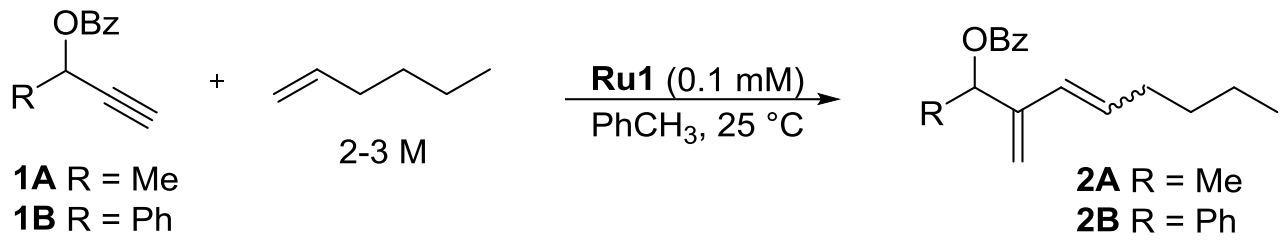

To determine if alkyne substitution had an effect on the rate of ene-yne metathesis, alkyne 1B was employed and compared to 1A (Table S5). The data showed that 1B had a $k_{o b s}$ of $0.00028 \mathrm{M} \mathrm{s}^{-1}$ at $2 \mathrm{M} 1$-hexene while alkyne $1 \mathrm{~A}$ had a $k_{\text {obs }}$ of $0.00078 \mathrm{M} \mathrm{s}^{-1}$ under identical conditions. This trend was consistent even at $3 \mathrm{M} \mathrm{1-}$ hexene with an observed 3-fold larger rate for 1A versus 1B. Overlaid kinetic runs of the two alkynes at $2 \mathrm{M}$ 1-hexene (Figure S14) demonstrated full consumption of the alkyne with zero-order dependence on the alkyne concentration.

Table S5. Data Summary for Alkynes 1A and 1B.

\begin{tabular}{|c|c|c|c|}
\hline [Alkyne], 0.08 M & {$[1-$ hexene], M } & [Ru1], M & $k_{\text {obs }}, \mathrm{M} \mathrm{s}^{-1}$ \\
\hline 1A & 2 & 0.0001 & $0.00078( \pm 0.00011)$ \\
\hline 1A & 3 & 0.0001 & $0.0012( \pm 0.0002)$ \\
\hline 1B & 2 & 0.0001 & $0.00028( \pm 0.00001)$ \\
\hline 1B & 3 & 0.0001 & $0.00040( \pm 0.00001)$ \\
\hline
\end{tabular}

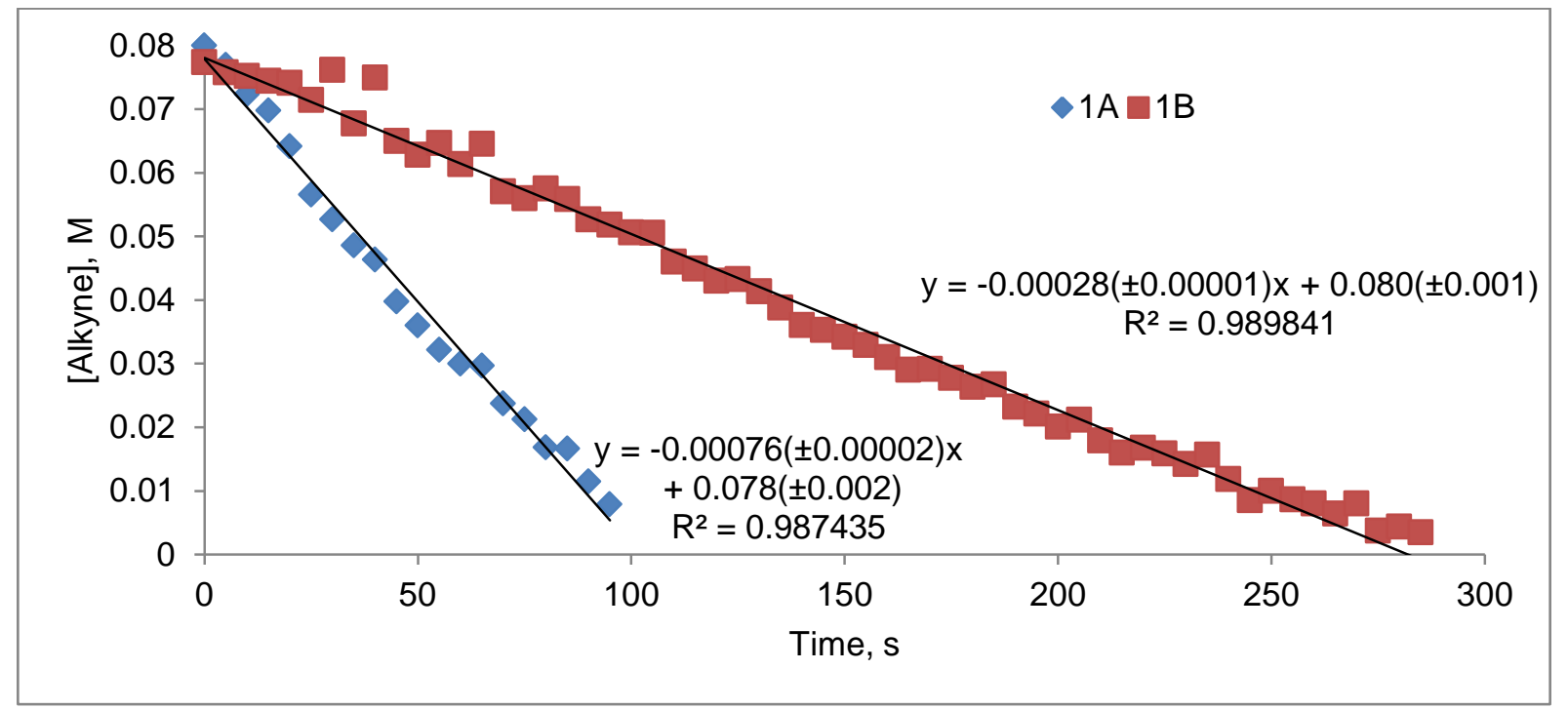

Figure S14. Single Runs of 1A $\left(k_{o b s}=0.00076 \mathrm{M} \mathrm{s}^{-1}\right)$ and 1B $\left(k_{o b s}=0.00028 \mathrm{M} \mathrm{s}^{-1}\right)$ by IR. Conditions: $0.08 \mathrm{M}$ [Yne], $2 \mathrm{M}$ [1-hexene], $0.0001 \mathrm{M}$ [Ru1], toluene, $25^{\circ} \mathrm{C}$. 


\section{Competition Study}

Analogous to the GC study performed previously, for alkynes 1A and 1B a competition study was carried out to evaluate if catalyst decomposition led to the observed rate difference. The data in Figure S15 demonstrated that the rates for the two alkynes were comparable under competitive conditions (1A $k_{o b s}=0.00063 \mathrm{M} \mathrm{s}^{-1}$ and $\mathbf{1 B}$ $k_{o b s}=0.00022 \mathrm{M} \mathrm{s}^{-1}$ ) to that of the individual runs above (Table S5, $1 \mathrm{~A} k_{\text {obs }}=0.00078 \mathrm{M}$ $\mathrm{s}^{-1}$ and 1B $k_{o b s}=0.00028 \mathrm{M} \mathrm{s}^{-1}$ ), thus ruling out that catalyst decomposition affects the measured rate of the reaction.

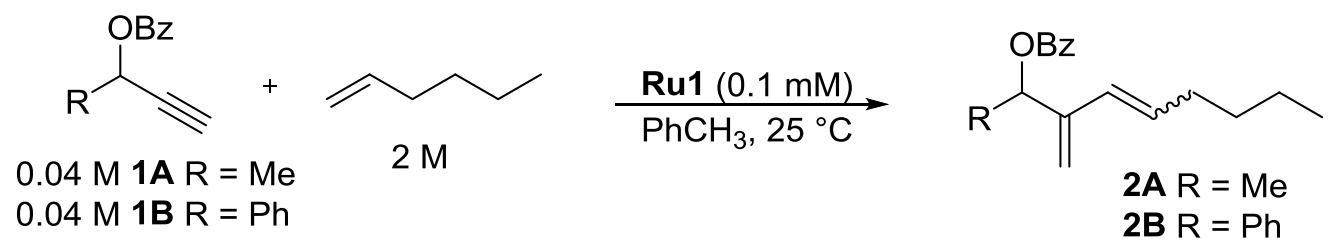

$$
2 B R=P h
$$

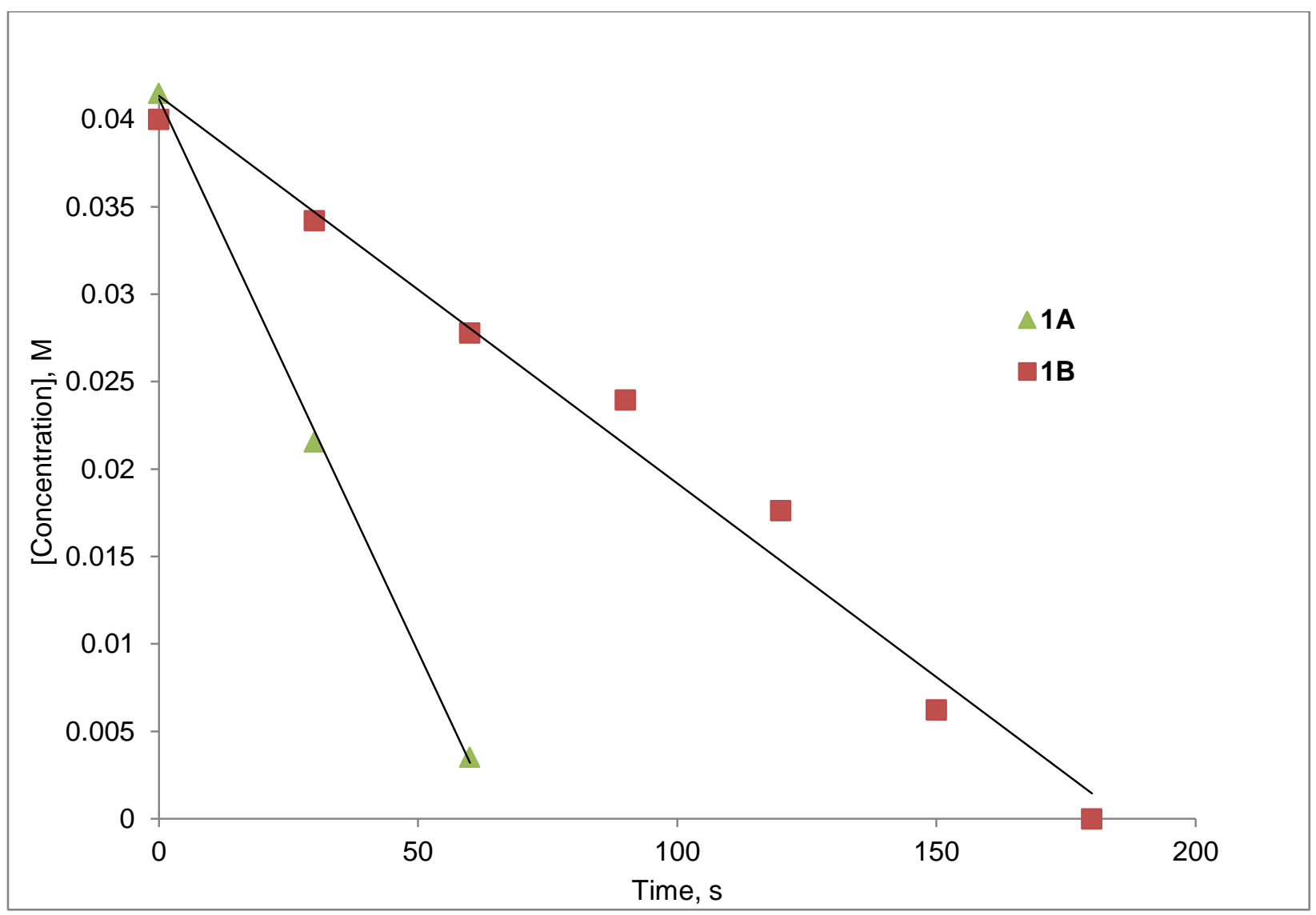

Figure S15. Competition Study. Conditions: 0.04 M 1A, 0.04 M 1B, 2 M 1-hexene, $0.0001 \mathrm{M}$ Ru1, toluene, $25{ }^{\circ} \mathrm{C}, 0.08 \mathrm{M}$ dodecane as internal standard. Aliquots were quenched with carbon monoxide and analyzed by GC. For $1 \mathrm{~A} k_{o b s}=0.00063 \mathrm{M} \mathrm{s}^{-1}$ and for 1B $k_{\text {obs }}=0.00022 \mathrm{M} \mathrm{s}^{-1}$. 


\section{Characterization of $\mathbf{2 B}$}

Compound 2B: Isolated as a slightly yellow oil by column chromatography in a $76 \%$ yield. Analytically pure sample was obtained by preparative layer TLC (eluted three times with 5\% EtOAc/hexanes). Analytical TLC: $\mathrm{R}_{\mathrm{f}} 0.5$ (10\% EtOAc/hexanes); ${ }^{1} \mathrm{H}$ NMR $\left(500 \mathrm{MHz}, \mathrm{CDCl}_{3}, \mathrm{ppm}\right): \delta 8.08(\mathrm{~d}, J=7.5 \mathrm{~Hz}, 2 \mathrm{H}), 7.55(\mathrm{t}, J=7.3 \mathrm{~Hz}, 1 \mathrm{H}), 7.46(\mathrm{~d}, J$ $=7.8 \mathrm{~Hz}, 2 \mathrm{H}$ ), 7.43 (t, $J=7.8 \mathrm{~Hz}, 2 \mathrm{H}), 7.34$ (t, $J=7.3 \mathrm{~Hz}, 2 \mathrm{H}$ ), 7.30 (d, J=7.3 Hz, 1 H), $6.75(\mathrm{~s}, 1 \mathrm{H}), 6.02(\mathrm{~d}, J=16.1 \mathrm{~Hz}, 1 \mathrm{H}), 5.78(\mathrm{dt}, J=6.8,16.1 \mathrm{~Hz}, 1 \mathrm{H}), 5.28(\mathrm{~s}, 1$ H), $5.25(\mathrm{~s}, 1 \mathrm{H}$ ), 2.01 (q, $J=6.8 \mathrm{~Hz}, 2 \mathrm{H}$ ), 1.26 (quintet, $J=7.3 \mathrm{~Hz}, 2 \mathrm{H}$ ), 1.20 (sextet, $J$ $=7.3 \mathrm{~Hz}, 2 \mathrm{H}), 0.81(\mathrm{t}, J=7.3 \mathrm{~Hz}, 3 \mathrm{H}) ;{ }^{13} \mathrm{C}\left\{{ }^{1} \mathrm{H}\right\} \mathrm{NMR}\left(75 \mathrm{MHz}, \mathrm{CDCl}_{3}, \mathrm{ppm}\right): \delta 165.46$, $144.25,138.66,133.12$, 133.02, 130.28, 129.73, 128.50, 128.39, 128.07, 127.55, 114.30, 75.64, 32.71, 31.20, 22.04, 13.85; FT-IR (thin film, $\mathrm{cm}^{-1}$ ): 3033, 2957, 2927 , 2857, 1722, 1603, 1495, 1451, 1314, 1266, 1176, 1108, 1070, 1026, 967, 901,711, 699; High-resolution MS (EI, m/z) molecular ion calculated for $\left[\mathrm{C}_{22} \mathrm{H}_{24} \mathrm{O}_{2}\right]^{+} 320.1771$, found 320.1773 , error $0.6 \mathrm{ppm}$.

Internal Alkyne

The data shown below in Figure S16 and Figure S17 is of single runs and the data outlined in Figure $\mathrm{S} 18$ is of duplicate runs. Use of an internal alkyne exhibited curved plots suggestive of first-order dependency in [alkyne] (Figure S16). Plotting $\ln [15]$ vs. time, gave a linear plot with the slope $=-\mathrm{k} \mathrm{in} \mathrm{s}^{-1}$ (Figure S17). The data in Table S6 was then used to generate Figure S18. Using this data, [alkene] dependency was determined to be first-order (Figure S18B, slope $=0.87$ for $\ln ($ rate) vs. $\operatorname{In}[$ alkene] plot). Additionally at the lower alkene loading (1 M 1-hexene), full consumption of alkyne was observed. Precatalyst dependency was not studied for this alkyne.

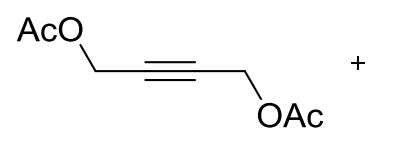

$15,0.08 \mathrm{M}$

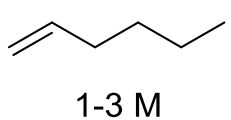

1-3 M

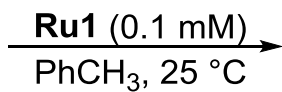

$\mathrm{PhCH}_{3}, 25^{\circ} \mathrm{C}$

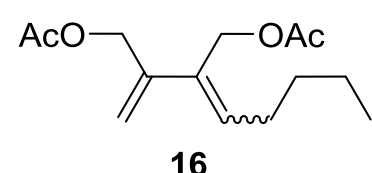

16

Table S6. Data Summary for Internal Alkyne 15.

\begin{tabular}{l|c|c|c|c|}
\hline Entry & [Ru1], M & {$[\mathbf{1 5}], \mathrm{M}$} & {$[1$-hexene], M } & $k_{\text {obs }, ~} \mathrm{~s}^{-1}$ \\
\hline 1 & 0.0001 & 0.08 & 1 & 0.00717 \\
\hline 2 & 0.0001 & 0.08 & 2 & 0.0134 \\
\hline 3 & 0.0001 & 0.08 & 3 & 0.0188 \\
\hline \multicolumn{7}{|l}{ Conditions: 0.08M 15, 1-3 M 1-hexene, 0.0001 M Ru1, toluene, 25} \\
${ }^{\circ} \mathrm{C}$. Error for the measurements is 5\%.
\end{tabular}




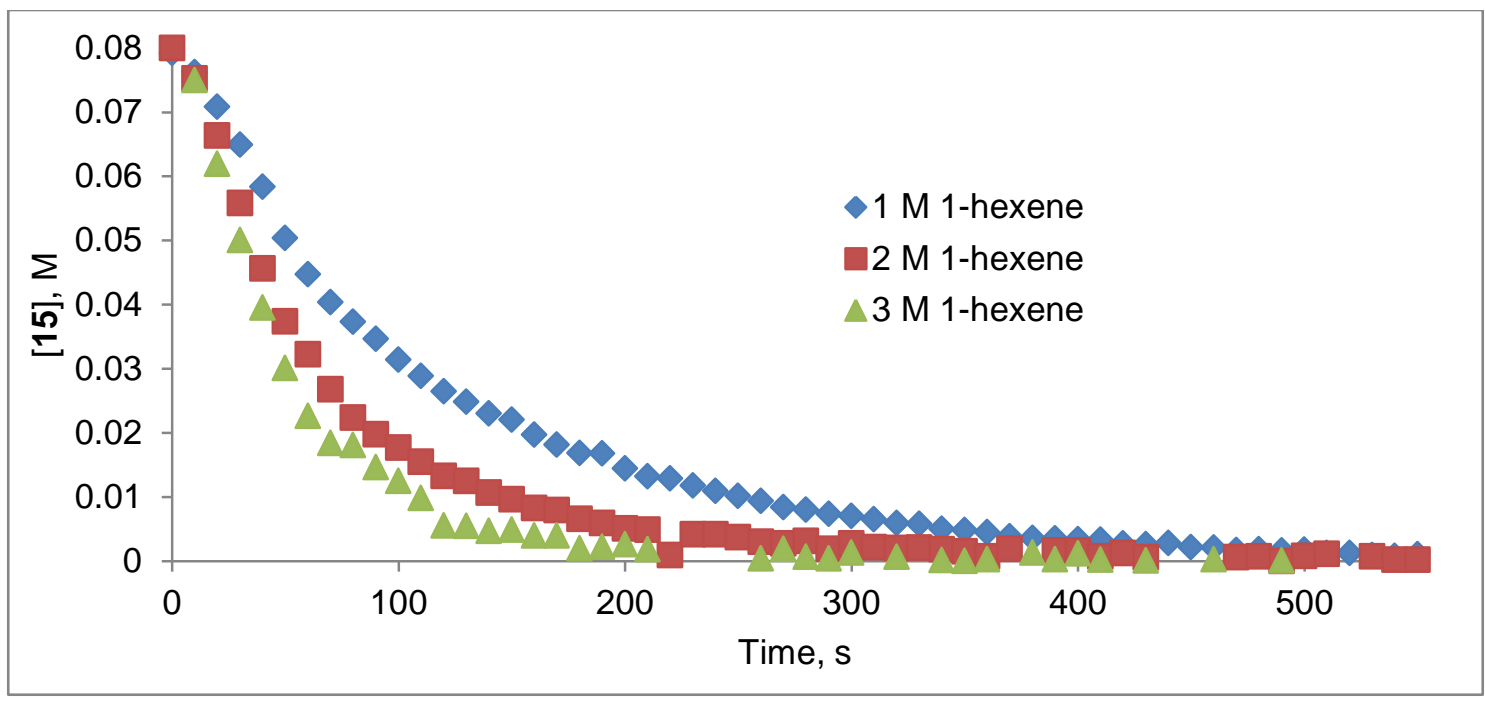

Figure S16. Representative Plot of 1-Hexene-15 Metathesis. Conditions: 0.08 M [15], 1$3 \mathrm{M}$ [1-hexene], $0.0001 \mathrm{M}$ [Ru1], toluene, $25^{\circ} \mathrm{C}$.

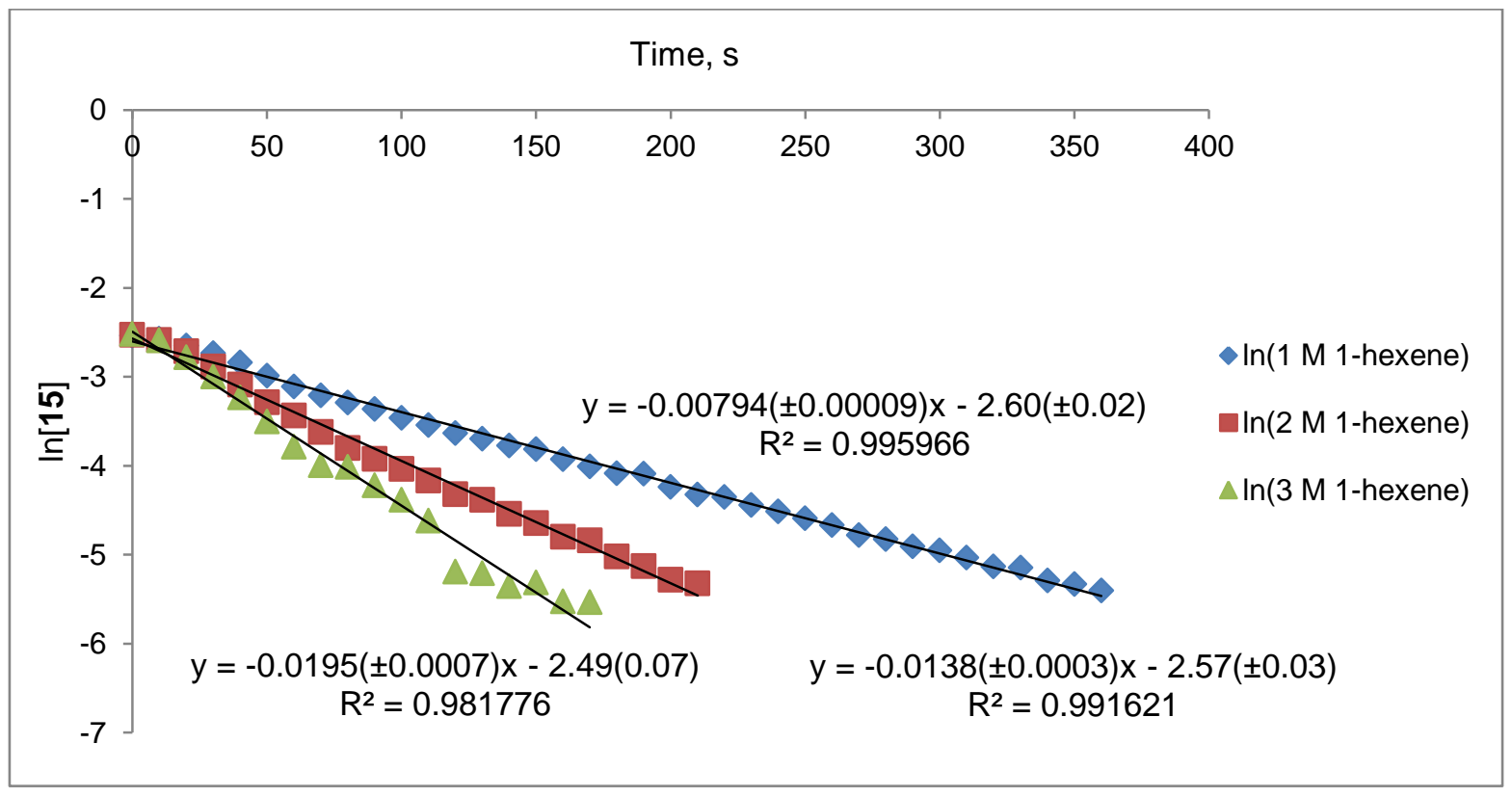

Figure S17. Ln[15] vs. Time. Gave a linear plot with the slope represents $k_{o b s}$ in $\mathrm{s}^{-1}$. At 1 $\mathrm{M} 1$-hexene the $k_{o b s}$ was $0.00794 \mathrm{~s}^{-1}$, at $2 \mathrm{M} 1$-hexene the $k_{o b s}$ was $0.01384 \mathrm{~s}^{-1}$, and at 3 $\mathrm{M}$ 1-hexene the $k_{o b s}$ was $0.0195 \mathrm{~s}^{-1}$ 


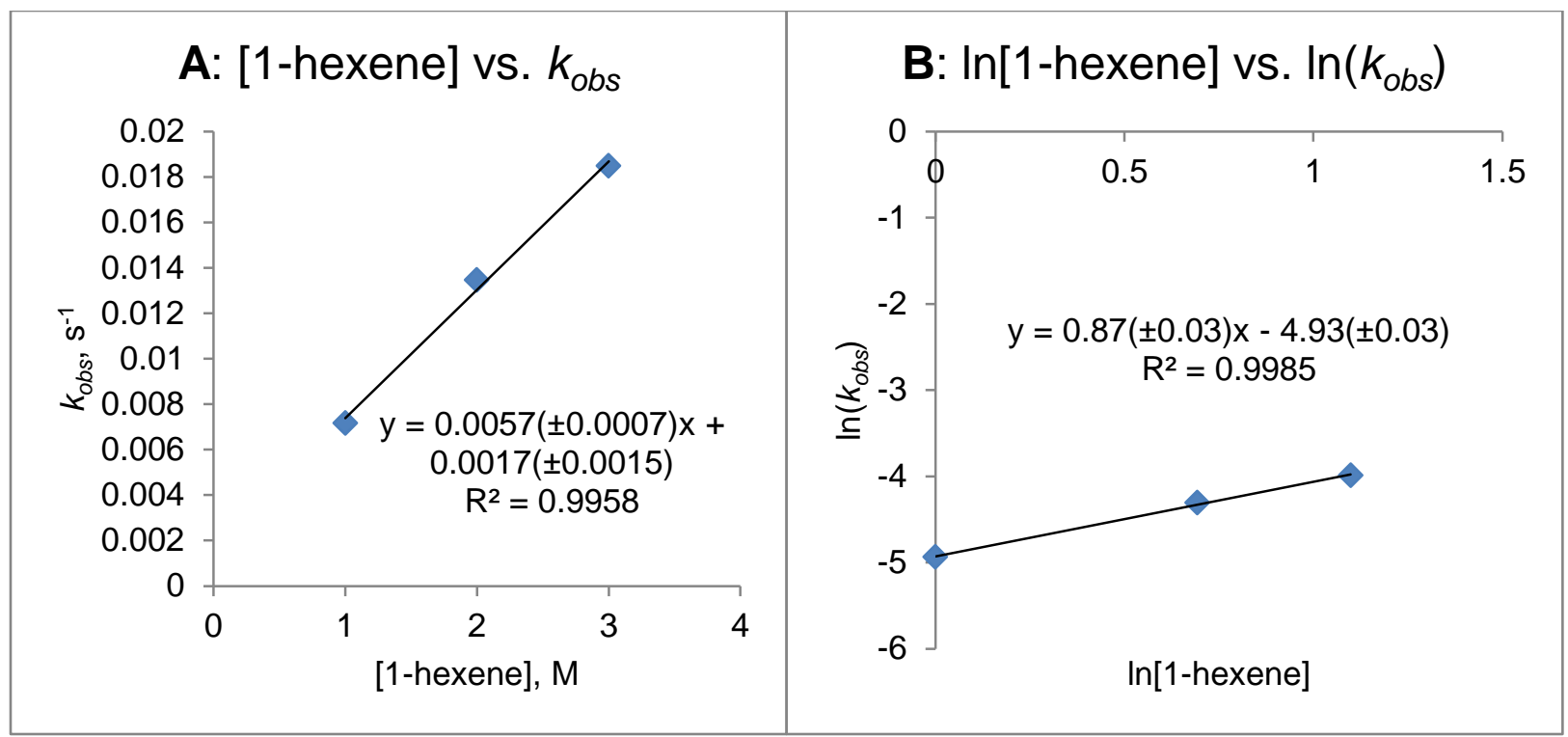

Figure S18. Determination of Alkene Dependency. Conditions: $0.08 \mathrm{M} \mathrm{15}, 1-3 \mathrm{M} 1$ hexene, $0.0001 \mathrm{M}$ Ru1, toluene, $25^{\circ} \mathrm{C}$. A: $k_{o b s}$ vs. [1-hexene] showed no saturation and a linear increase in rate with higher [1-hexene] concentration, $y$-intercept $=0.0017$; $\mathbf{B}$ : $\ln \left(k_{\text {obs }}\right)$ vs. $\ln [1$-hexene] displayed first order dependency, slope $=0.87$.

\section{Characterization of 16}

Compound 16: Isolated as a clear oil by column chromatography $(0-10 \%$ EtOAc/hexanes) as a $2: 1 \mathrm{E}-\mathrm{Z}$ mixture in $85 \%$ yield. Analytical TLC: $\mathrm{R}_{\mathrm{f}} 0.4(20 \%$ EtOAc/hexanes); ${ }^{1} \mathrm{H}$ NMR (500 MHz, $\mathrm{CDCl}_{3}, \mathrm{ppm}$ ): $\delta 5.83$ (t, $J=7.8 \mathrm{~Hz}, 0.33 \mathrm{H}$ ), 5.67 $(\mathrm{t}, J=7.3 \mathrm{~Hz}, 0.67 \mathrm{H}), 5.32(\mathrm{~d}, J=1.5 \mathrm{~Hz}, 0.67 \mathrm{H}), 5.25(\mathrm{~s}, 0.33 \mathrm{H}), 5.23(\mathrm{~s}, 0.33 \mathrm{H})$, $5.01(\mathrm{~s}, 0.67 \mathrm{H}), 4.81(\mathrm{~s}, 0.66 \mathrm{H}), 7.76(\mathrm{~s}, 0.66 \mathrm{H}), 4.61(\mathrm{~s}, 1.34 \mathrm{H}), 4.58(\mathrm{~s}, 1.34 \mathrm{H})$, $2.23(\mathrm{q}, J=7.3 \mathrm{~Hz}, 0.66 \mathrm{H}), 2.09$ (q, $J=7.2 \mathrm{~Hz}, 1.34 \mathrm{H}), 2.09(\mathrm{~s}, 0.99 \mathrm{H}), 2.07$ (s, 2.01 $\mathrm{H}), 2.05(\mathrm{~s}, 0.99 \mathrm{H}), 2.04(\mathrm{~s}, 2.01 \mathrm{H}), 1.48-1.28(\mathrm{~m}, 2 \mathrm{H}), 0.91(\mathrm{t}, J=7.3 \mathrm{~Hz}, 0.99 \mathrm{H})$, 0.89 (t, $J=7.3 \mathrm{~Hz}, 2.01 \mathrm{H}) ;{ }^{13} \mathrm{C}\left\{{ }^{1} \mathrm{H}\right\}\left(75 \mathrm{MHz}, \mathrm{CDCl}_{3}, \mathrm{ppm}\right): \delta 170.97,170.65,170.46$, 141.33, 140.48, 135.41, 134.59, 133.41, 131.49, 116.99, 114.43, 77.22, 67.78, 65.74, $65.24,59.76,31.77,31.60,28.41,28.01,22.29,22.26,20.96,20.85,13.91,13.88$; FTIR (thin film, $\mathrm{cm}^{-1}$ ): 2959, 2874, 1740, 1639, 1458, 1371, 1225, 1027, 965, 911, 730; High-resolution MS $\left(\mathrm{ESI}^{+}, \mathrm{m} / \mathrm{z}\right)$ molecular ion calculated for $\left[\mathrm{C}_{14} \mathrm{H}_{22} \mathrm{O}_{4}\right]^{+} 254.1513$, found 254.1514, error $0.5 \mathrm{ppm}$. 
Linear Unbranched Alkyne

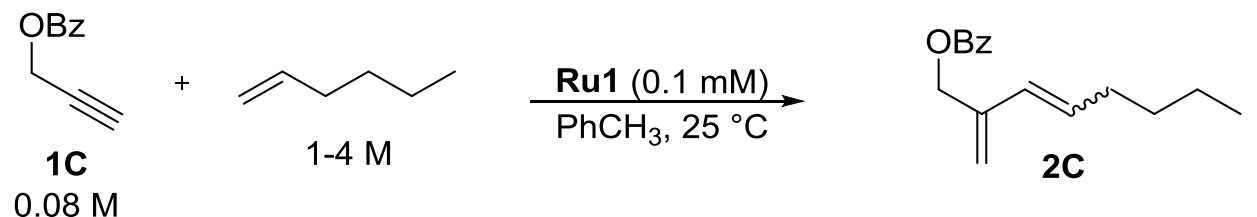

For propargyl benzoate (1C) full conversion to diene was never observed under the conditions outlined in this paper. Single runs were completed and percent conversion was established by proton NMR using mesitylene as an internal standard. The data is shown in Table S7. First-order dependency on alkene was observed from the plot of $\ln \left(k_{o b s}\right)$ vs. In[alkene] plot (Figure S19B). Linear consumption of alkyne was observed for reactions going to higher conversion (2-4 M 1-hexene), indicating a zeroorder dependence on alkyne. Precatalyst dependency was not studied for this system. Use of 1,2-dichloroethane as solvent with higher precatalyst loadings only showed complete conversions at high 1-hexene concentrations ( $>4 \mathrm{M})$.

Table S7. 1C-1-Hexene Metathesis Data.

\begin{tabular}{|c|c|c|c|c|c|c|c|}
\hline Entry & $\begin{array}{c}{[\mathbf{1 C}],} \\
\mathrm{M}\end{array}$ & $\begin{array}{c}{[1-\text { hexene], }} \\
\mathrm{M}\end{array}$ & $\begin{array}{c}{[\text { Ru1 }],} \\
\mathrm{M}\end{array}$ & $\begin{array}{c}k_{\text {obs }} \text { (initial } \\
\text { rate), } \mathrm{M} \mathrm{s}^{-1}\end{array}$ & $\begin{array}{c}\operatorname{In}[1- \\
\text { hexene] }\end{array}$ & $\begin{array}{c}\% \\
\ln \left(k_{\text {obs }}\right)\end{array}$ & $\begin{array}{c}\% \\
\text { Conversion }\end{array}$ \\
\hline $1^{\mathrm{a}}$ & 0.08 & 1 & 0.0001 & 0.00010 & 0.00 & -9.22 & 9 \\
\hline $2^{\mathrm{a}}$ & 0.08 & 2 & 0.0001 & 0.00023 & 0.69 & -8.38 & 30 \\
\hline $3^{\mathrm{a}}$ & 0.08 & 3 & 0.0001 & 0.00038 & 1.10 & -7.89 & 50 \\
\hline $4^{\mathrm{a}}$ & 0.08 & 4 & 0.0001 & 0.00052 & 1.39 & -7.56 & 70 \\
\hline
\end{tabular}




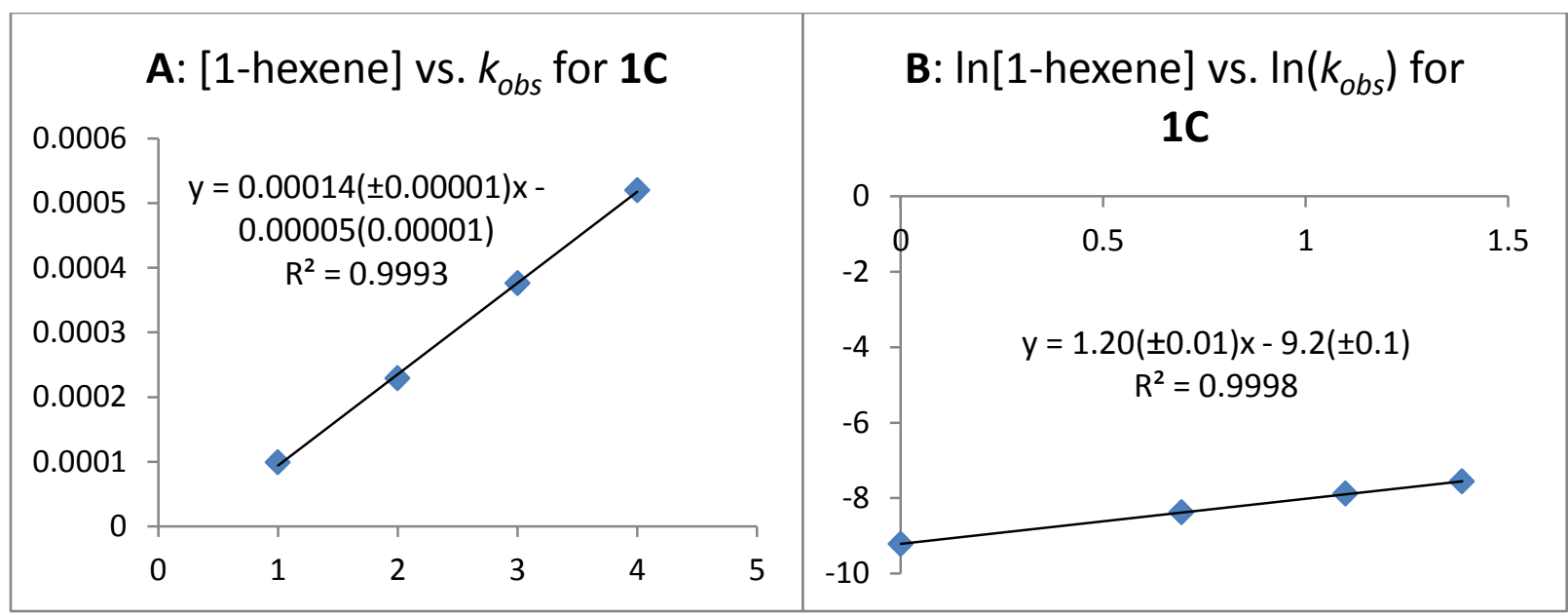

Figure S19. Determination of Alkene Dependency for 1C. Conditions: $0.08 \mathrm{M}$ [1C], 1$4 \mathrm{M}$ [1-hexene], $0.0001 \mathrm{M}$ [Ru1], toluene, $25{ }^{\circ} \mathrm{C}$. A: $k_{\text {obs }}$ vs. [1-hexene] showed no saturation and a linear increase in rate with higher [1-hexene] concentration, $y$-intercept $=0.00005 ; \mathbf{B}: \ln \left(k_{o b s}\right)$ vs. $\ln [1$-hexene] displayed first order dependency, slope = 1.2.

When the reaction was run in 1,2-dichloroethane using the conditions outlined in equation 11, incomplete conversion was observed by ReactIR ${ }^{\mathrm{TM}}$. Percent conversion was assessed using ${ }^{1} \mathrm{H}$ NMR with mesitylene as an internal standard after alkyne consumption was no longer observed. The reaction solvent was removed, mesitylene $(0.08 \mathrm{mmol}, 11.1 \mu \mathrm{L})$ was added and the sample was dissolved in $\mathrm{CDCl}_{3}$ for $\mathrm{NMR}$ analysis. Percent conversion was determined by integration of the product $2 \mathrm{C}(\mathrm{E} / \mathrm{Z}$ mixture) at $6.13 \mathrm{ppm}(\mathrm{d}, J=15.0 \mathrm{~Hz})$ and $5.88 \mathrm{ppm}(\mathrm{d}, J=12.0 \mathrm{~Hz})$, the butadiene at $6.45 \mathrm{ppm}(\mathrm{dd}, J=11.1,17.8 \mathrm{~Hz})$, and the alkyne $1 \mathrm{C}$ at $2.53 \mathrm{ppm}(\mathrm{t}, J=4 \mathrm{~Hz}$ ) versus mesitylene at $6.8 \mathrm{ppm}(\mathrm{s})$. At $1 \mathrm{M} 1$-hexene, a $50 \% \mathrm{NMR}$ yield of product $2 \mathrm{C}$ was observed as an $E / Z$ mixture with $45 \%$ of the starting alkyne remaining. At $4 \mathrm{M} 1$-hexene full consumption of the alkyne occurred with $71 \%$ of the desired product $\mathbf{2 C}$ and $29 \%$ of the butadiene present. The data is summarized in eq 11. 

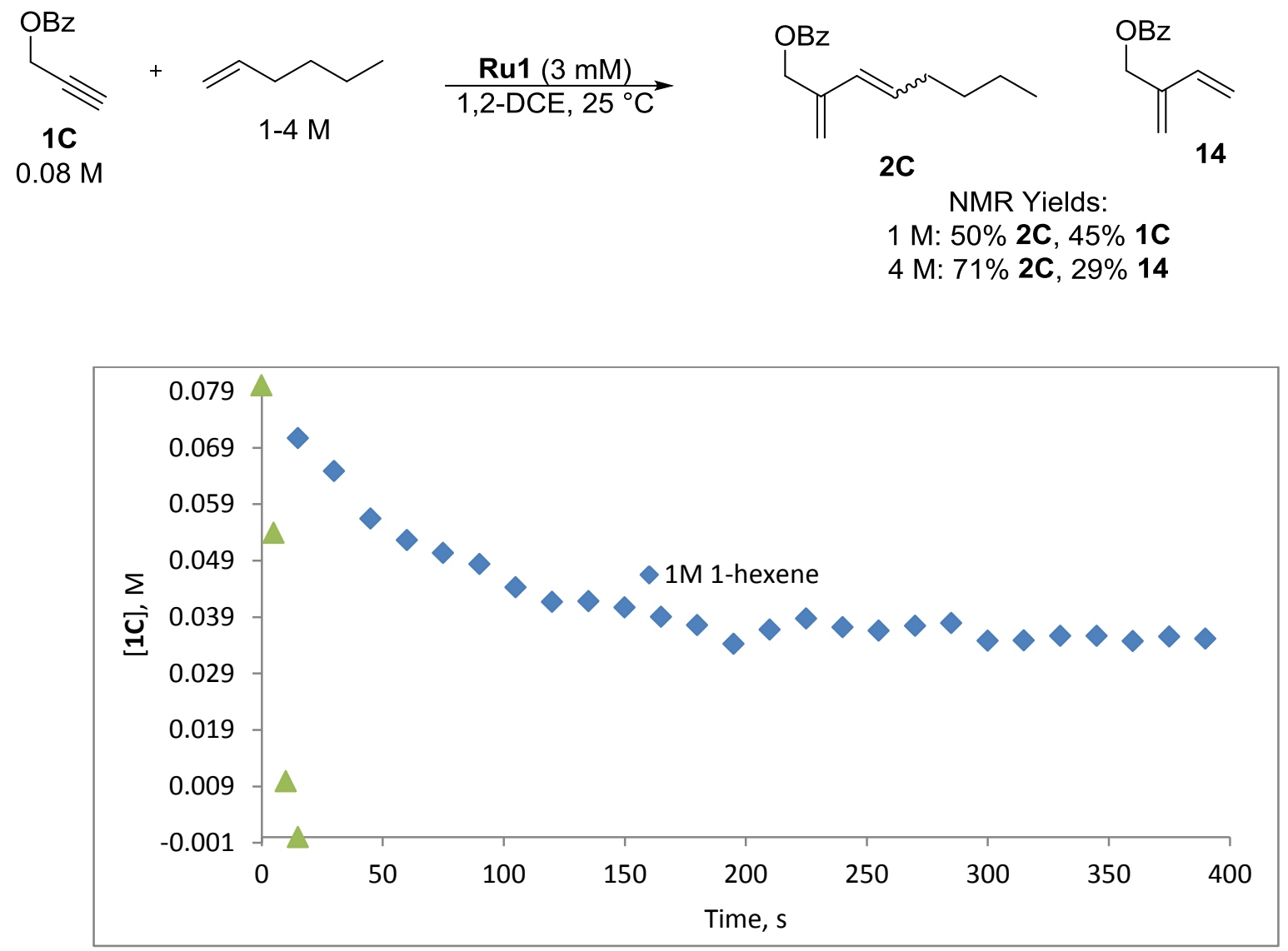

Figure S20. Plot of [1C] vs. Time. Conditions: $0.08 \mathrm{M}$ [1C], 1-4 M [1-hexene], $0.003 \mathrm{M}$ [Ru1], toluene, $25^{\circ} \mathrm{C}$. Percent conversion was determined by NMR with an internal standard. 


\section{G. Precatalyst Comparison}

Next the ene-yne metathesis of 1A with 1-hexene was evaluated using the Grela catalyst (Ru2). The data is shown in Table S8. The data obtained over the alkene range (1-4 M 1-hexene) is plotted against that observed for Ru1 in Figure S21.

Table S8. Kinetic Data for 1-Hexene-Alkyne (1A) Metathesis using Ru2.

\begin{tabular}{|c|c|c|c|c|c|}
\hline Entry & {$[$ Ru2], M } & {$[\mathbf{1 A}], \mathrm{M}$} & {$[1$-hexene], M } & $k_{\text {obs, }} \mathrm{M} \mathrm{s}^{-1}$ & $k_{E Y M}, \mathrm{M}^{-1} \mathrm{~s}^{-1}$ \\
\hline $1^{\mathrm{a}}$ & 0.0001 & 0.08 & 1 & 0.000589 & 5.9 \\
\hline $2^{\mathrm{a}}$ & 0.0001 & 0.08 & 1 & 0.000426 & 4.3 \\
\hline $3^{\mathrm{a}}$ & 0.0001 & 0.08 & 1 & 0.000410 & 4.1 \\
\hline $4^{\mathrm{a}}$ & 0.0001 & 0.08 & 1 & 0.000448 & 4.5 \\
\hline $5^{\mathrm{a}}$ & 0.0001 & 0.08 & 1 & 0.000627 & 6.3 \\
\hline 6 & 0.0001 & 0.08 & 2 & 0.000755 & 3.8 \\
\hline 7 & 0.0001 & 0.08 & 2 & 0.000717 & 3.6 \\
\hline 8 & 0.0001 & 0.08 & 2 & 0.00116 & 5.8 \\
\hline 9 & 0.0001 & 0.08 & 2 & 0.00077 & 3.9 \\
\hline 10 & 0.0001 & 0.08 & 3 & 0.00130 & 4.3 \\
\hline 11 & 0.0001 & 0.08 & 3 & 0.00127 & 4.3 \\
\hline 12 & 0.0001 & 0.08 & 3 & 0.00155 & 5.2 \\
\hline 13 & 0.0001 & 0.08 & 4 & 0.00241 & 6.0 \\
\hline 14 & 0.0001 & 0.08 & 4 & 0.00197 & 4.9 \\
\hline 15 & 0.0001 & 0.08 & 4 & 0.00198 & 5.0 \\
\hline 16 & 0.0001 & 0.08 & 4 & 0.00250 & 6.3 \\
\hline
\end{tabular}




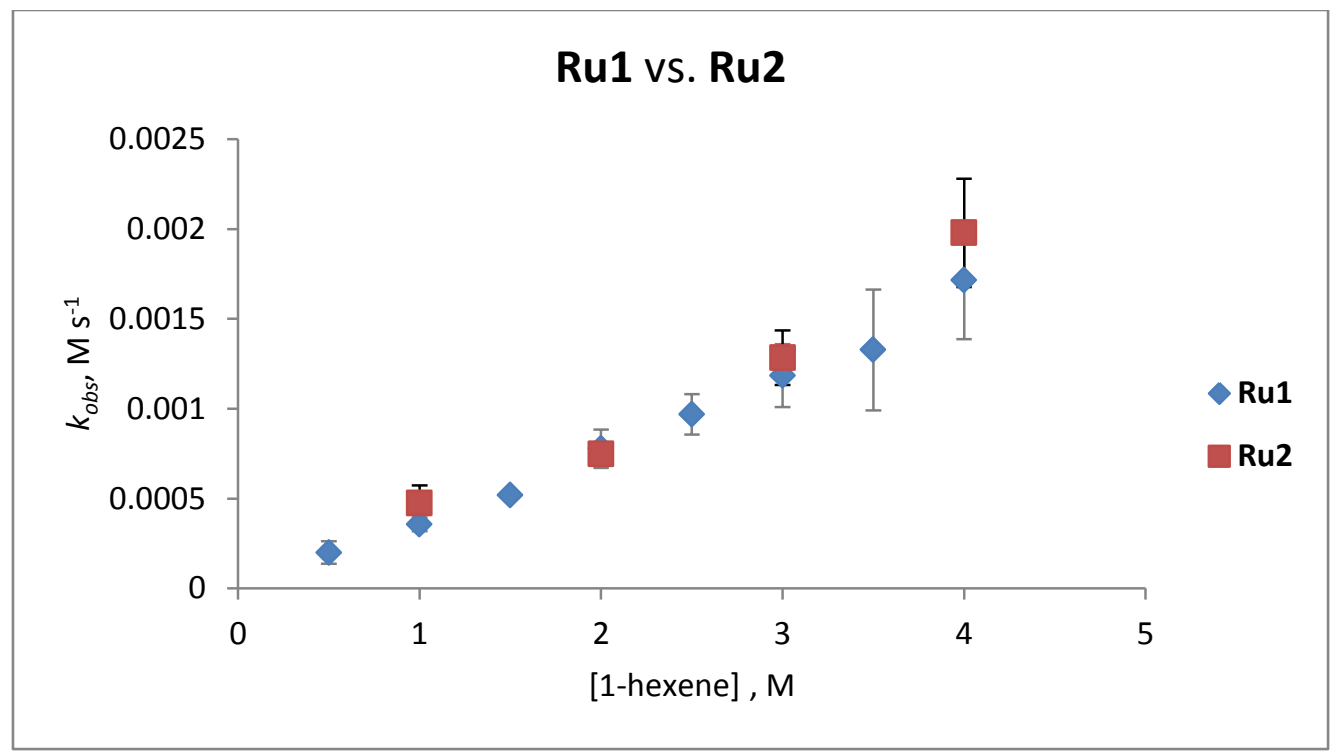

Figure S21. Hoveyda (Ru1) vs. Grela (Ru2) Precatalyst. Conditions: 0.08 M [1A], 1-4 M [1-hexene], $0.0001 \mathrm{M}$ [Precatalyst], toluene, $25^{\circ} \mathrm{C}$.

\section{H. Quenching Studies}

Scheme S1. Synthesis of $4^{6,7}$

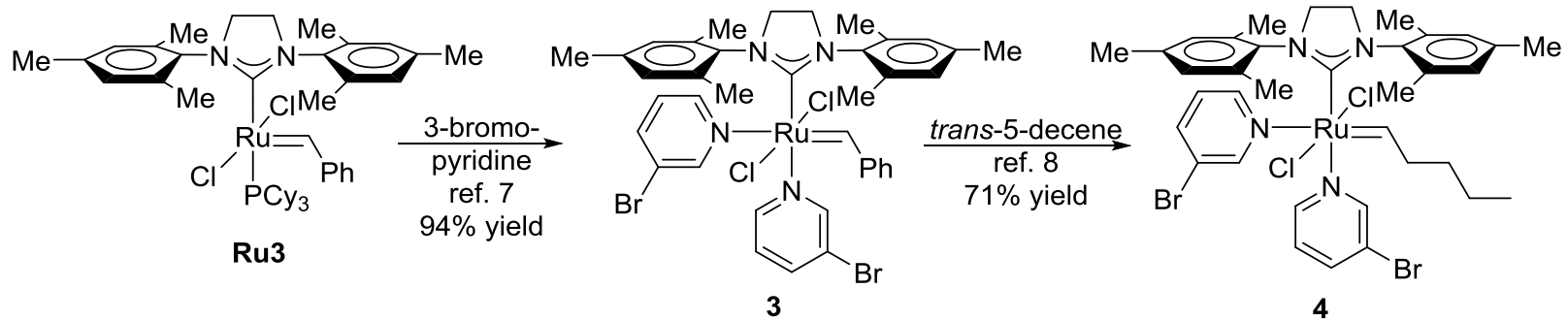

Procedure: Alkylidene 4 was synthesized by dissolving $100 \mathrm{mg}$ of $3(0.113 \mathrm{mmol}$, 1 equiv) in $6.5 \mathrm{~mL}$ of dichloromethane followed by addition of $244 \mu \mathrm{L}$ of trans-5-decene (1.27 mmol, 11.25 equiv) under argon at room temperature. The solution was stirred for 2 minutes then placed under high vacuum to remove volatiles. The resulting brown solid was sonicated with pentanes, filtered and washed with pentanes until the washings were colorless. Pentylidene 4 was isolated as a light brown solid ( $69 \mathrm{mg}, 71 \%$ yield). ${ }^{1} \mathrm{H}$ $\operatorname{NMR}\left(\mathrm{C}_{6} \mathrm{D}_{6}, 300 \mathrm{MHz}, \mathrm{ppm}\right) \delta 19.77$ (t, $J=5.4 \mathrm{~Hz}, 1 \mathrm{H}$ ), 9.24 (br s, $2 \mathrm{H}$ ), 8.86 (br s, 2 H), $7.52(\mathrm{~s}, 6 \mathrm{H}), 6.40$ (br s, $2 \mathrm{H}), 3.6-3.8(\mathrm{~m}, 4 \mathrm{H}), 3.10(\mathrm{~s}, 6 \mathrm{H}), 2.91(\mathrm{~s}, 6 \mathrm{H}), 2.80$ (q, J $=13.5,7.8 \mathrm{~Hz}, 2 \mathrm{H}), 2.51(\mathrm{~s}, 6 \mathrm{H}), 1.4-1.7(\mathrm{~m}, 6 \mathrm{H}), 1.11(\mathrm{t}, J=7.2 \mathrm{~Hz}, 3 \mathrm{H}) .{ }^{13} \mathrm{C}\left\{{ }^{1} \mathrm{H}\right\}$ $\operatorname{NMR}\left(\mathrm{C}_{6} \mathrm{D}_{6}, 75 \mathrm{MHz}, \mathrm{ppm}\right) \delta 339.5,220.2,152.2,149.3,139.6,138.4,138.0,137.7$, $137.5,135.7,130.6,129.6$, 129.5, 138.5, 124.1, 120.0, 60.0, 51.2, 50.8, 32.7, 32.2, $28.7,22.83,22.5,21.1,20.3,19.0,14.2$. As seen by Sponsler, ${ }^{7}$ decomposition of the 
alkylidene may cause some signals to be obscured. Due to product instability, elemental analysis was not performed.

Scheme S2. Synthesis of Pentylidene Insertion Product 6
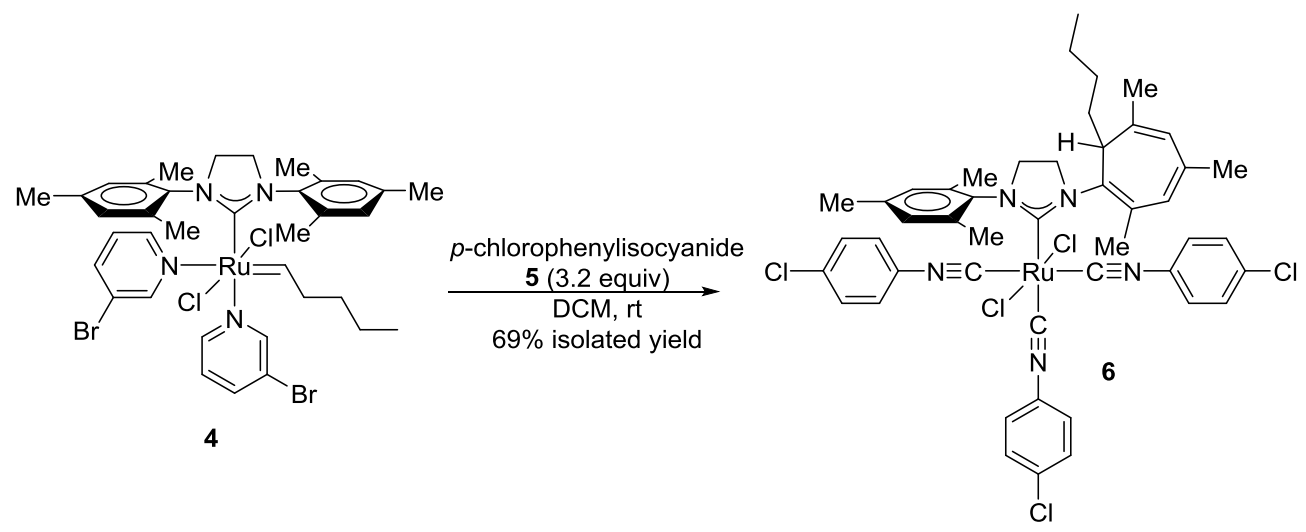

To an oven-dried $20 \mathrm{~mL}$ vial was added the pentylidene pyridine solvate 4 (50 $\mathrm{mg}, 0.0578 \mathrm{mmol}$ ) and dichloromethane $(2 \mathrm{~mL})$ with a magnetic stir bar. To the stirring solution at room temperature was added $p$-chlorophenylisocyanide $5(25.5 \mathrm{mg}, 0.185$ mmol, 3.2 equiv) in $0.2 \mathrm{~mL}$ of dichloromethane. The solution underwent an instantaneous color change from brown to bright yellow and the mixture was allowed to stir for a further 10 minutes. Then $10 \mathrm{~mL}$ of pentanes was added to precipitate the organometallic complex out of solution. The solvent was decanted and another $10 \mathrm{~mL}$ of pentanes was added and the solid was sonicated and filtered. The solid was washed with pentanes until the washing were clear. The isolated yellow solid was determined to be $\sim 95 \%$ pure by ${ }^{1} \mathrm{H}$ NMR. In order to obtain analytically pure material the organometallic complex was purified by column chromatography (5\% to $35 \%$ EtOAc/hexanes). The product 5 was isolated as a bright yellow powder (38 $\mathrm{mg}, 69 \%$ yield). Analytical TLC: $\mathrm{R}_{\mathrm{f}} 0.75$ (50\% EtOAc/hexanes); ${ }^{1} \mathrm{H}$ NMR $\left(400 \mathrm{MHz}, \mathrm{CDCl}_{3}, \mathrm{ppm}\right)$ : ס 7.35-7.31 (m, $6 \mathrm{H}), 7.19(\mathrm{~s}, 1 \mathrm{H}), 7.17(\mathrm{~s}, 1 \mathrm{H}), 7.10(\mathrm{~s}, 1 \mathrm{H}), 7.08(\mathrm{~s}, 1 \mathrm{H}), 6.78(\mathrm{~s}, 1$ $\mathrm{H}), 6.58(\mathrm{~s}, 1 \mathrm{H}), 5.82\left(\mathrm{~s}, 1 \mathrm{H}, \mathrm{CH}_{\mathrm{CHT}}\right), 5.53\left(\mathrm{~s}, 1 \mathrm{H}, \mathrm{CH}_{\mathrm{CHT}}\right), 3.77-3.6(\mathrm{~m}, 4 \mathrm{H}), 3.32(\mathrm{~d}, J$ $\left.=10.8 \mathrm{~Hz}, 1 \mathrm{H}, \mathrm{CH}_{\text {alkylCHT }}\right), 2.51(\mathrm{~s}, 3 \mathrm{H}), 2.47(\mathrm{~s}, 3 \mathrm{H}), 2.05(\mathrm{~s}, 3 \mathrm{H}), 2.04(\mathrm{~s}, 3 \mathrm{H}), 1.85$ $(\mathrm{s}, 3 \mathrm{H}), 1.82(\mathrm{~s}, 3 \mathrm{H}), 1.36-1.06(\mathrm{~m}, 6 \mathrm{H}), 0.82(\mathrm{t}, J=6.8 \mathrm{~Hz}, 3 \mathrm{H})$; FT-IR-ATR $\left(\mathrm{cm}^{-1}\right)$ : 2152, 2080, 2006, 1484, 1406, 1256, 1089, 1012, 836, 798, 537; Anal. Calcd for $\mathrm{C}_{47} \mathrm{H}_{48} \mathrm{Cl}_{5} \mathrm{~N}_{5} \mathrm{Ru}: \mathrm{C}, 58.72 ; \mathrm{H}, 5.03 ; \mathrm{Cl}, 18.44 ; \mathrm{N}, 7.29$. Found: $\mathrm{C}, 58.81 ; \mathrm{H}, 5.11 ; \mathrm{Cl}$, 18.78; N, 7.32. 
Scheme S3. Synthesis of methylidene insertion product 10

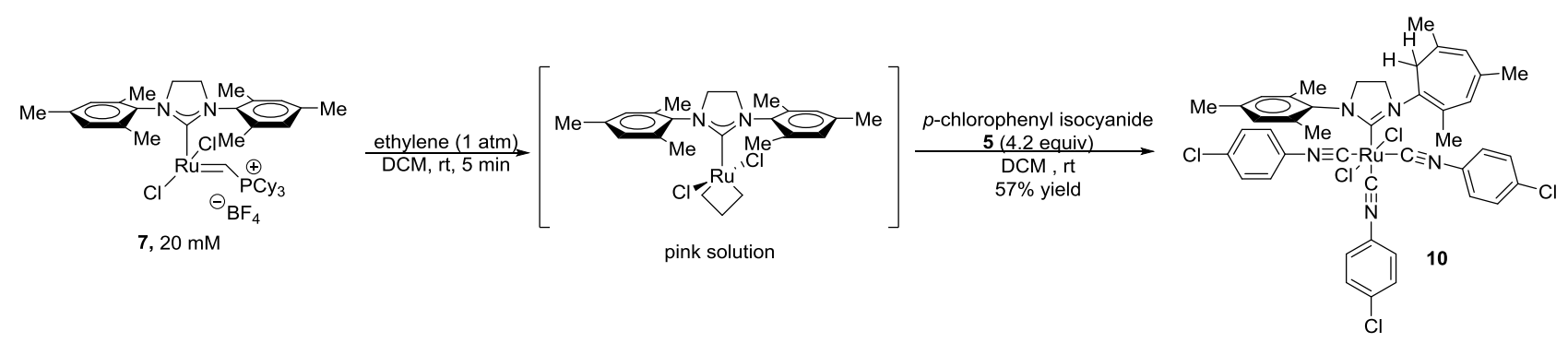

To a $10 \mathrm{~mL}$ oven dried RBF was added the Piers catalyst 7 (48 mg, $0.056 \mathrm{mmol}$, 1 equiv) and dichloromethane $(2.75 \mathrm{~mL})$. A balloon of ethylene was then attached to the flask and the solution was sparged the solution for $30 \mathrm{~s}$ followed by keeping the flask under a balloon atmosphere (ethylene) for 1 minute. The solution underwent a color change from brown to pink, at which time p-chlorophenylisocyanide (32 mg, 0.235 mmol, 4.2 equiv) was added as a solution using $0.2 \mathrm{~mL}$ of dichloromethane. A rapid color change was observed from pink to yellow. The sample was then crashed out of solution by addition of pentanes $(10 \mathrm{~mL})$ followed by cooling at $-20{ }^{\circ} \mathrm{C}$ overnight. The solution was decanted away from the precipitate and pentanes $(5 \mathrm{~mL})$ was added and the solid was sonicated and filtered to give pure 10 as a light brown solid (29 $\mathrm{mg}, 57 \%$ yield). ${ }^{1} \mathrm{H}$ NMR $\left(500 \mathrm{MHz}, \mathrm{CDCl}_{3}, \mathrm{ppm}\right): \delta 7.35(\mathrm{~m}, 4 \mathrm{H}), 7.23(\mathrm{~m}, 5 \mathrm{H}), 7.14(\mathrm{~m}, 3 \mathrm{H})$, $6.75(\mathrm{~s}, 1 \mathrm{H}), 6.73(\mathrm{~s}, 1 \mathrm{H}), 5.84\left(\mathrm{~s}, 1 \mathrm{H}, \mathrm{CH}_{\mathrm{CHT}}\right), 5.65\left(\mathrm{~s}, 1 \mathrm{H}, \mathrm{CH}_{\mathrm{CHT}}\right), 3.82-3.98(\mathrm{~m}, 2$ $\left.\mathrm{H}, \mathrm{NCH}_{2}\right), 3.71-3.77\left(\mathrm{~m}, 2 \mathrm{H}, \mathrm{CH}_{\mathrm{CHT}} / \mathrm{NCH}_{2}\right), 3.61\left(\mathrm{~m}, 1 \mathrm{H}, \mathrm{NCH}_{2}\right), 2.57(\mathrm{~d}, J=13.0 \mathrm{~Hz}, 1$ $\left.\mathrm{H}, \mathrm{CH}_{\mathrm{CHT}}\right), 2.55(\mathrm{~s}, 3 \mathrm{H}), 2.53(\mathrm{~s}, 3 \mathrm{H}), 2.09(\mathrm{~s}, 3 \mathrm{H}), 2.05(\mathrm{~s}, 3 \mathrm{H}), 1.85(\mathrm{~s}, 3 \mathrm{H}), 1.81$ (s, $3 \mathrm{H}$ ); FT-IR-ATR $\left(\mathrm{cm}^{-1}\right): 2150,2074,1484,1404,1256,1088,1012,835,824,798$; Anal. Calcd for $\mathrm{C}_{43} \mathrm{H}_{40} \mathrm{Cl}_{5} \mathrm{~N}_{5} \mathrm{Ru}$ : C, 57.06; H, 5.45; Cl, 19.58; N, 7.74. Found: C, 57.12; $\mathrm{H}, 4.49 ; \mathrm{Cl}, 19.50 ; \mathrm{N}, 7.78$. 
Isocyanide quenching studies:

Using the kinetic conditions outlined by Plenio, ${ }^{5}$ a UV-Vis experiment was carried out to assess reproducibility under identical conditions ( $0.1 \mathrm{mM}$ Ru1, $0.05 \mathrm{M}$ 1-hexene, Toluene, $30^{\circ} \mathrm{C}$, Plenio: $k_{o b s}=0.00484 \mathrm{~s}^{-1}$, This work: $\left.k_{o b s}=0.0044 \mathrm{~s}^{-1}\right)$. Following this data an isocyanide quenching reaction was then carried out on a $0.006 \mathrm{mmol}$ scale of the Hoveyda-Grubbs precatalyst. To an oven-dried $100 \mathrm{~mL}$ jacketed reaction vessel was added 1-hexene ( $375 \mu \mathrm{L}, 3 \mathrm{mmol}$ ) and $59 \mathrm{~mL}$ of toluene with a magnetic stir bar under an argon atmosphere. The solution was equilibrated at $30^{\circ} \mathrm{C}$ for 15 minutes using a thermostat-controlled water circulator. The Hoveyda precatalyst Ru1 (3.8 mg, 0.006 $\mathrm{mmol}$ ) was added as a solution in $0.6 \mathrm{~mL}$ of toluene and allowed to stir for either 4 or 24 minutes. Then the initiation process was quenched by the addition of $p$ chlorophenylisocyanide ( $16.5 \mathrm{mg}, 0.12 \mathrm{mmol}, 20$ equiv) in $200 \mu \mathrm{L}$ of toluene. The solvent was then removed by placing under high vacuum while cooling the solution in an ice bath. Once the toluene was removed, trimethylorthoformate $(0.656 \mu \mathrm{L}, 0.006$ $\mathrm{mmol}$ ) was added to serve as an internal standard for ${ }^{1} \mathrm{H}$ NMR analysis in chloroform- $d$. In the ${ }^{1} \mathrm{H}$ NMR, no evidence of the pentylidene $\mathbf{6}$ or the methylidene $\mathbf{1 0}$ were observed in either reaction. The only observed products were that of the Hoveyda insertion products 13 and free 2-isopropoxystyrene 11.

Scheme S4. Isocyanide Quenching of UV-Vis Initiation Reactions
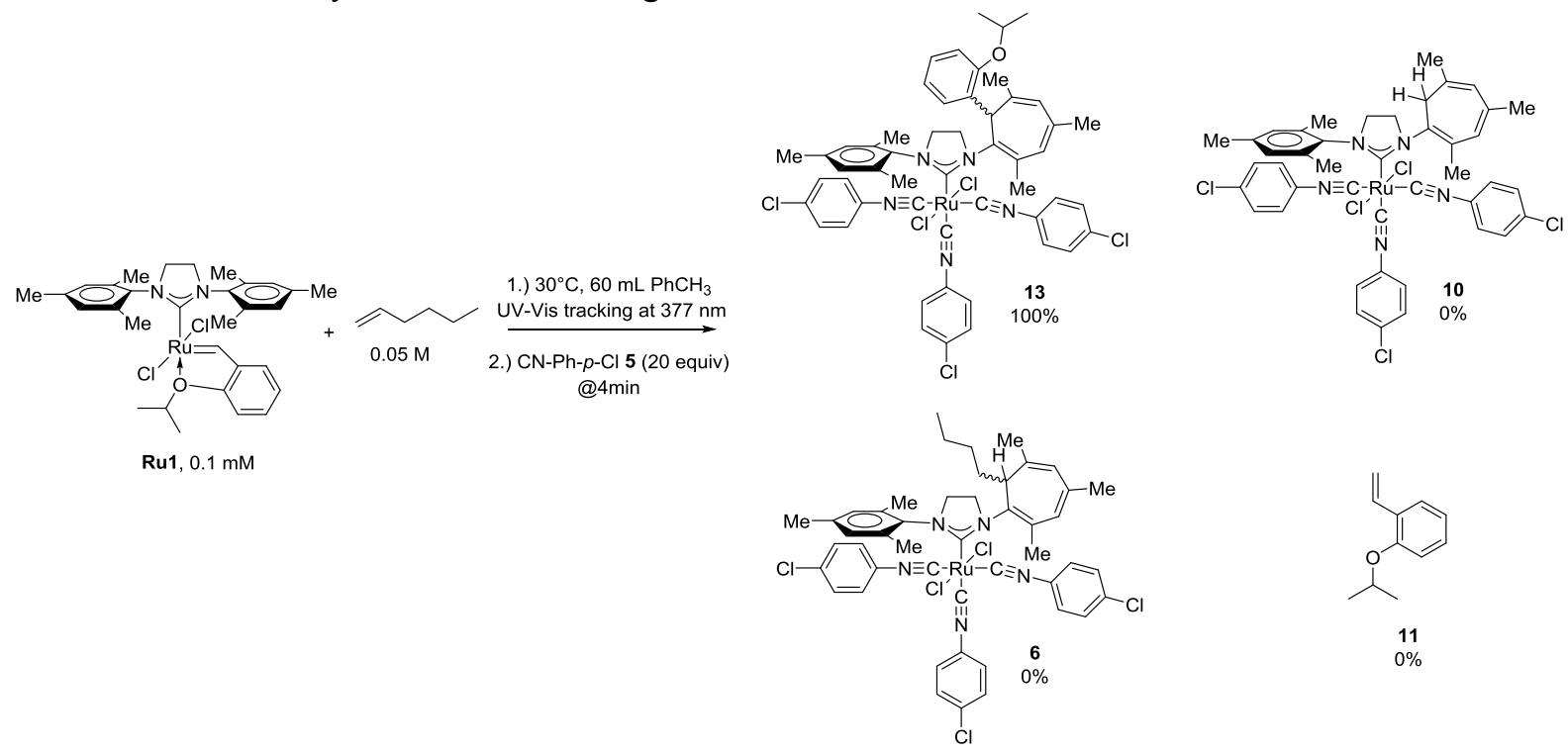

(12) 

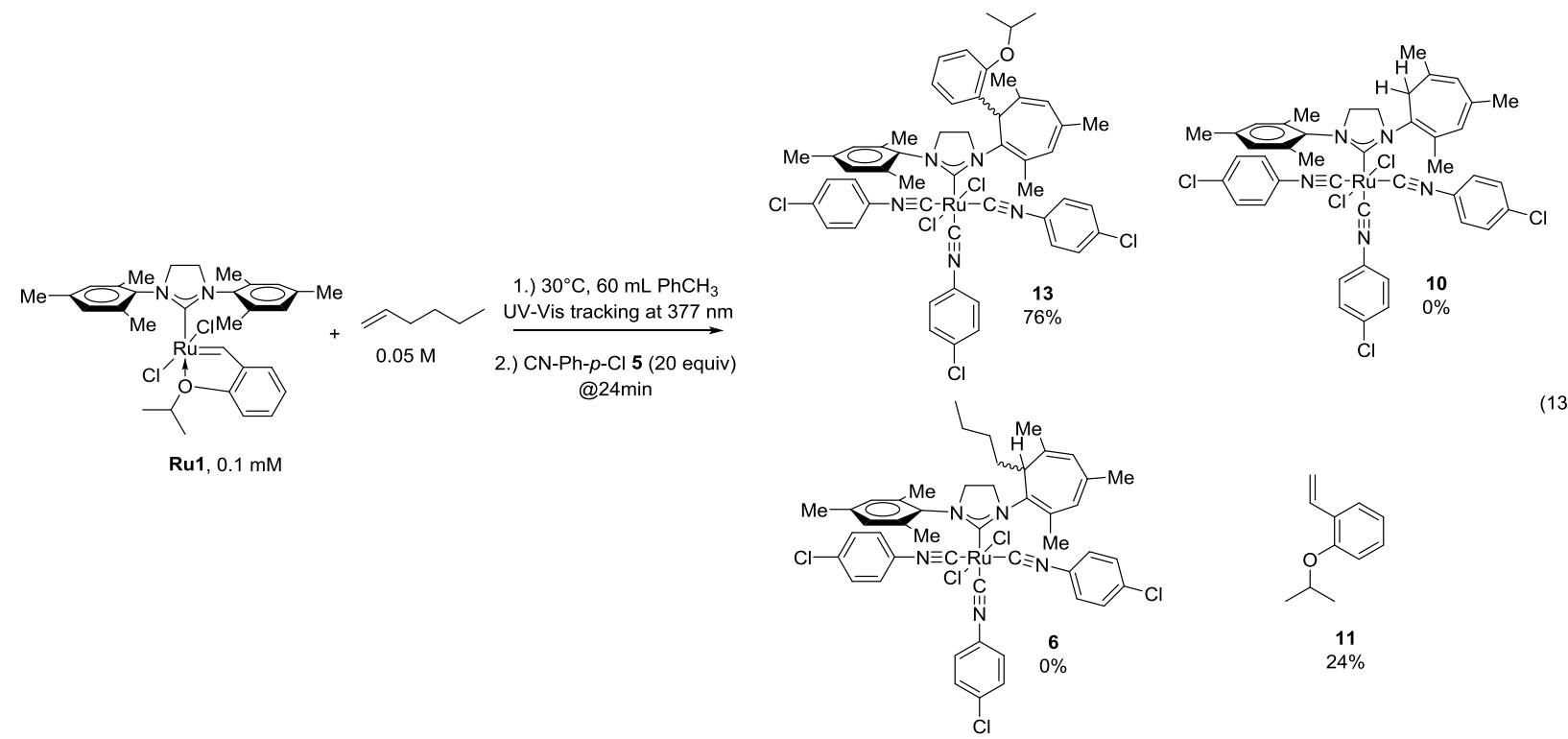

Additional UV-Vis studies were performed to establish the rate of initiation of Ru1 over a range of 1-hexene concentrations with and without alkyne present. The data is presented below in Table S9 and Table S10.

Table S9. Initiation Rates of Ru1 for Olefin Metathesis. Conditions: toluene, $25^{\circ} \mathrm{C}$, data shown is an average of 3 runs and the error for the measurements was found to be $5 \%$.

\begin{tabular}{|c|c|c|}
\hline [Ru1], M & [1-hexene], M & $k_{\text {obs }}, \mathrm{s}^{-1}$ \\
\hline 0.0001 & 1 & 0.0139 \\
\hline 0.0001 & 2 & 0.0217 \\
\hline 0.0001 & 3 & 0.0299 \\
\hline 0.0001 & 4 & 0.0371 \\
\hline
\end{tabular}

Table S10. Initiation Rates of Ru1 for Ene-yne Metathesis. Conditions: toluene, $25^{\circ} \mathrm{C}$, data shown is an average of 2 runs and the error for the measurements was found to be $5 \%$.

\begin{tabular}{|c|c|c|c|}
\hline [1A], M & [Ru1], M & [1-hexene], M & $k_{\text {obs }}, \mathrm{s}^{-1}$ \\
\hline 0.08 & 0.0001 & 1 & 0.0283 \\
\hline 0.08 & 0.0001 & 2 & 0.0351 \\
\hline 0.08 & 0.0001 & 3 & 0.0402 \\
\hline 0.08 & 0.0001 & 4 & 0.0437 \\
\hline
\end{tabular}


Starting with the pentylidene pyridine solvate 4 a variety of conditions were used to evaluate the extent of 2-isopropoxystyrene $\mathbf{1 1}$ rebound in solution under phosphine free conditions. General conditions used are outlined in Scheme S5. Below that is outlined the procedures for each run with a graphical display of the results in Scheme S6.

Scheme S5. 2-Isopropoxystyrene Rebound Studies
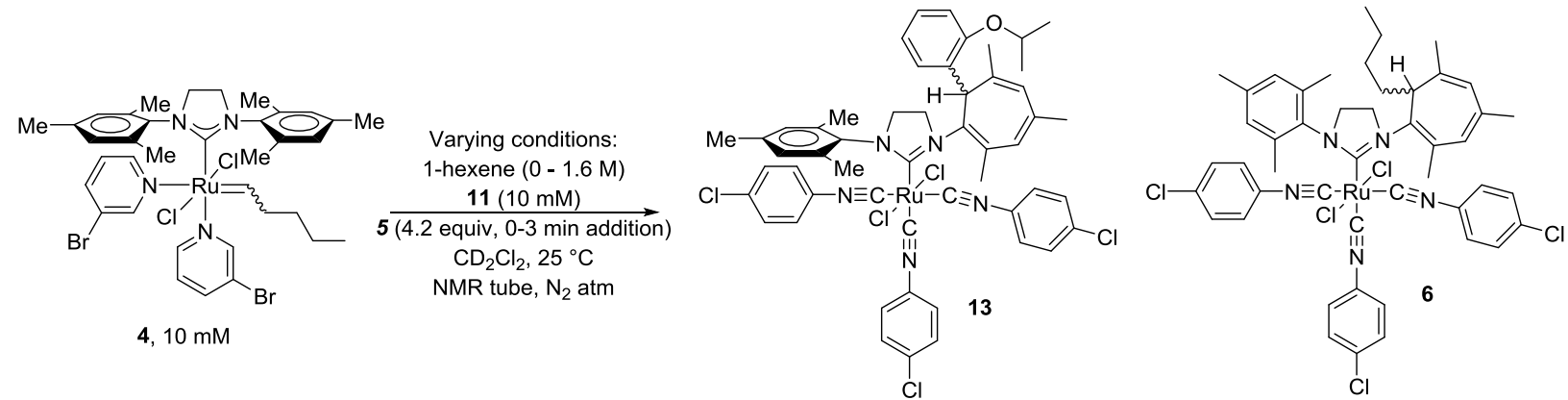

(a) In an oven-dried screw cap NMR tube was added 4 (5.2 $\mathrm{mg}, 0.006 \mathrm{mmol}, 1$ equiv) with $0.4 \mathrm{~mL}$ of $\mathrm{CD}_{2} \mathrm{Cl}_{2}$ under an inert atmosphere at $25^{\circ} \mathrm{C}$. In one portion was added 2-isopropoxystyrene ( $1.1 \mu \mathrm{L}, 0.006 \mathrm{mmol}, 1$ equiv) and $p$-chlorophenylisocyanide (3.5 mg, $0.0252 \mathrm{mmol}, 4.2$ equiv) in $200 \mu \mathrm{L}$ of $\mathrm{CD}_{2} \mathrm{Cl}_{2}$. An instantaneous color change was observed from brown to yellow. Mesitylene $(0.002 \mathrm{mmol}, 2.8 \mu \mathrm{L}$ of a $10 \%$ solution in $\mathrm{CD}_{2} \mathrm{Cl}_{2}$ ) was added and the reaction was analyzed by ${ }^{1} \mathrm{H}$ NMR.

(b) In an oven-dried screw cap NMR tube was added 4 (5.2 $\mathrm{mg}, 0.006 \mathrm{mmol}, 1$ equiv) with $0.5 \mathrm{~mL}$ of $\mathrm{CD}_{2} \mathrm{Cl}_{2}$ under an inert atmosphere at $25^{\circ} \mathrm{C}$. In one portion was added 2-isopropoxystyrene $\left(1.1 \mu \mathrm{L}, 0.006 \mathrm{mmol}, 1\right.$ equiv) in $100 \mu \mathrm{L}$ of $\mathrm{CD}_{2} \mathrm{Cl}_{2}$. The solution was shaken for 1 minute then $p$-chlorophenylisocyanide $(3.5 \mathrm{mg}, 0.0252 \mathrm{mmol}$, 4.2 equiv) in $50 \mu \mathrm{L}$ of $\mathrm{CD}_{2} \mathrm{Cl}_{2}$ was added to quench the carbene. An instantaneous color change was observed from brown to yellow. Mesitylene $(0.002 \mathrm{mmol}, 2.8 \mu \mathrm{L}$ of a $10 \%$ solution in $\mathrm{CD}_{2} \mathrm{Cl}_{2}$ ) was added and the reaction was analyzed by ${ }^{1} \mathrm{H}$ NMR.

(c) In an oven-dried screw cap NMR tube was added 4 (5.2 $\mathrm{mg}, 0.006 \mathrm{mmol}, 1$ equiv) with $0.4 \mathrm{~mL}$ of $\mathrm{CD}_{2} \mathrm{Cl}_{2}$ under an inert atmosphere at $25^{\circ} \mathrm{C}$. In one portion was added 2-isopropoxystyrene $(1.1 \mu \mathrm{L}, 0.006 \mathrm{mmol}, 1$ equiv) and 1-hexene $(60 \mu \mathrm{L}, 0.48$ mmol, 80 equiv) with $140 \mu \mathrm{L}$ of $\mathrm{CD}_{2} \mathrm{Cl}_{2}$. The solution was shaken for 1 minute then $p$ chlorophenylisocyanide ( $3.5 \mathrm{mg}, 0.0252 \mathrm{mmol}, 4.2$ equiv) in $50 \mu \mathrm{L}$ of $\mathrm{CD}_{2} \mathrm{Cl}_{2}$ was added to quench the carbene. An instantaneous color change was observed from brown to yellow. Mesitylene $\left(0.002 \mathrm{mmol}, 2.8 \mu \mathrm{L}\right.$ of a $10 \%$ solution in $\left.\mathrm{CD}_{2} \mathrm{Cl}_{2}\right)$ was added and the reaction was analyzed by ${ }^{1} \mathrm{H}$ NMR.

(d) In an oven-dried screw cap NMR tube was added 4 (5.2 $\mathrm{mg}, 0.006 \mathrm{mmol}, 1$ equiv) with $0.4 \mathrm{~mL}$ of $\mathrm{CD}_{2} \mathrm{Cl}_{2}$ under an inert atmosphere at $25^{\circ} \mathrm{C}$. In one portion was 
added 2-isopropoxystyrene ( $1.1 \mu \mathrm{L}, 0.006 \mathrm{mmol}, 1$ equiv) and 1-hexene (120 $\mu \mathrm{L}, 0.96$ mmol, 160 equiv) with $80 \mu \mathrm{L}$ of $\mathrm{CD}_{2} \mathrm{Cl}_{2}$. The solution was shaken for 1 minute then $p$ chlorophenylisocyanide ( $3.5 \mathrm{mg}, 0.0252 \mathrm{mmol}, 4.2$ equiv) in $50 \mu \mathrm{L}$ of $\mathrm{CD}_{2} \mathrm{Cl}_{2}$ was added to quench the carbene. An instantaneous color change was observed from brown to yellow. Mesitylene $\left(0.002 \mathrm{mmol}, 2.8 \mu \mathrm{L}\right.$ of a $10 \%$ solution in $\left.\mathrm{CD}_{2} \mathrm{Cl}_{2}\right)$ was added and the reaction was analyzed by ${ }^{1} \mathrm{H}$ NMR.

(e) In an oven-dried screw cap NMR tube was added 4 (5.2 $\mathrm{mg}, 0.006 \mathrm{mmol}, 1$ equiv) with $0.4 \mathrm{~mL}$ of $\mathrm{CD}_{2} \mathrm{Cl}_{2}$ under an inert atmosphere at $25^{\circ} \mathrm{C}$. In one portion was added 2-isopropoxystyrene $(1.1 \mu \mathrm{L}, 0.006 \mathrm{mmol}, 1$ equiv) and 1-hexene $(80 \mu \mathrm{L}, 0.48$ mmol, 80 equiv) with $140 \mu \mathrm{L}$ of $\mathrm{CD}_{2} \mathrm{Cl}_{2}$. The solution was shaken for 3 minutes then $p$ chlorophenylisocyanide ( $3.5 \mathrm{mg}, 0.0252 \mathrm{mmol}, 4.2$ equiv) in $50 \mu \mathrm{L}$ of $\mathrm{CD}_{2} \mathrm{Cl}_{2}$ was added to quench the carbene. An instantaneous color change was observed from brown to yellow. Mesitylene $\left(0.002 \mathrm{mmol}, 2.8 \mu \mathrm{L}\right.$ of a $10 \%$ solution in $\left.\mathrm{CD}_{2} \mathrm{Cl}_{2}\right)$ was added and the reaction was analyzed by ${ }^{1} \mathrm{H}$ NMR.

(f) In an oven-dried screw cap NMR tube was added 4 (5.2 $\mathrm{mg}, 0.006 \mathrm{mmol}, 1$ equiv) with $0.4 \mathrm{~mL}$ of $\mathrm{CD}_{2} \mathrm{Cl}_{2}$ under an inert atmosphere at $25^{\circ} \mathrm{C}$. In one portion was added 2-isopropoxystyrene $(1.1 \mu \mathrm{L}, 0.006 \mathrm{mmol}, 1$ equiv) and 1 -hexene $(80 \mu \mathrm{L}, 0.48$ mmol, 80 equiv) with $140 \mu \mathrm{L}$ of $\mathrm{CD}_{2} \mathrm{Cl}_{2}$. The solution was shaken for 3 minutes then $p$ chlorophenylisocyanide ( $11.2 \mathrm{mg}, 0.082 \mathrm{mmol}, 20$ equiv) in $50 \mu \mathrm{L}$ of $\mathrm{CD}_{2} \mathrm{Cl}_{2}$ was added to quench the carbene. An instantaneous color change was observed from brown to yellow. Mesitylene $\left(0.002 \mathrm{mmol}, 2.8 \mu \mathrm{L}\right.$ of a $10 \%$ solution in $\left.\mathrm{CD}_{2} \mathrm{Cl}_{2}\right)$ was added and the reaction was analyzed by ${ }^{1} \mathrm{H}$ NMR. 
Scheme S6. Pentylidene isocyanide quenching studies

Added together:

2-isopropoxystyrene

(1 equiv, $10 \mathrm{mM}$ )

$p$-chlorophenyl isocyanide

(a) 4

$(10 \mathrm{mM})$

(4.2 equiv, $42 \mathrm{mM}$ )

$\mathrm{CD}_{2} \mathrm{Cl}_{2}, 25^{\circ} \mathrm{C}$

13

6

NMR tube, $\mathrm{N}_{2}$ atm

$0 \% \quad 100 \%$

2-isopropoxystyrene

(b) $\quad \begin{gathered}4 \\ (10 \mathrm{mM})\end{gathered}$

$\begin{array}{ccc}\text { 2-isopropoxystyrene } & & \\ (1 \text { equiv, } 10 \mathrm{mM}) & 13 & 6 \\ {1 \mathrm{~min}:} } & 24 \% & 76 \%\end{array}$

p-chlorophenyl isocyanide

(4.2 equiv, $42 \mathrm{mM}$ )

$\mathrm{CD}_{2} \mathrm{Cl}_{2}, 25^{\circ} \mathrm{C}$

NMR tube, $\mathrm{N}_{2}$ atm

Added together:

2-isopropoxystyrene

(1 equiv, $10 \mathrm{mM}$ )

(c) $\quad(10 \mathrm{mM})$

$\underset{\text { 1-hexene (80 equiv, } 800 \mathrm{mM}}{\stackrel{\text { Added at } 1 \mathrm{~min}:}{\longrightarrow}}$

13

6

p-chlorophenyl isocyanide

$45 \% \quad 42 \%$

(4.2 equiv, $42 \mathrm{mM}$ )

$\mathrm{CD}_{2} \mathrm{Cl}_{2}, 25^{\circ} \mathrm{C}$

NMR tube, $\mathrm{N}_{2}$ atm

Added together:

2-isopropoxystyrene

(1 equiv, $10 \mathrm{mM}$ )

(d)

4

$(10 \mathrm{mM})$

$\stackrel{\text { 1-hexene (160 equiv, } 1600 \mathrm{mM} \text { ) }}{\longrightarrow}$

13

Added at 1 min:

$60 \%$

6

p-chlorophenyl isocyanide

(4.2 equiv, $42 \mathrm{mM}$ )

$\mathrm{CD}_{2} \mathrm{Cl}_{2}, 25^{\circ} \mathrm{C}$

NMR tube, $\mathrm{N}_{2}$ atm

Added together:

2-isopropoxystyrene

(1 equiv, $10 \mathrm{mM}$ )

(e) $\quad \stackrel{4}{\mathrm{mM}}$

1-hexene (80 equiv, $800 \mathrm{mM}$ )

Added at $3 \mathrm{~min}$ :

13

6

$p$-chlorophenyl isocyanide

(4.2 equiv, $42 \mathrm{mM}$ )

$\mathrm{CD}_{2} \mathrm{Cl}_{2}, 25^{\circ} \mathrm{C}$

NMR tube, $\mathrm{N}_{2}$ atm

Added together:

2-isopropoxystyrene

(1 equiv, $10 \mathrm{mM}$ )

$\underset{\text { 1-hexene (80 equiv, } 800 \mathrm{mM}}{\stackrel{\text { Added at } 1 \mathrm{~min}:}{\longrightarrow}}$

$42 \% \quad 55 \%$

$p$-chlorophenyl isocyanide

(20 equiv, $200 \mathrm{mM}$ )

$\mathrm{CD}_{2} \mathrm{Cl}_{2}, 25^{\circ} \mathrm{C}$

NMR tube, $\mathrm{N}_{2}$ atm 
Ene-yne Metathesis Quench

Isocyanide-promoted Buchner reaction was used to quench an ene-yne metathesis. Quenching at two different time intervals yielded similar results (Scheme S7). After 100 s, $40 \%$ conversion to product 2 A was found. After 200 s, $79 \%$ conversion to $2 A$ was found.

Scheme S7. Ene-Yne Metathesis Isocyanide Quenching Studies
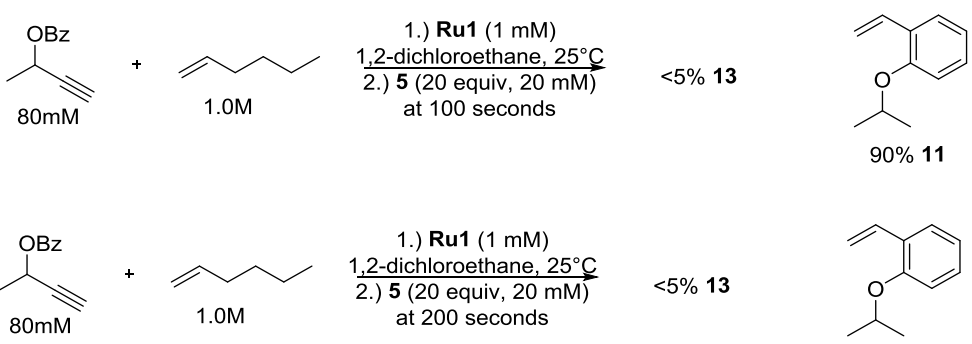

(14)
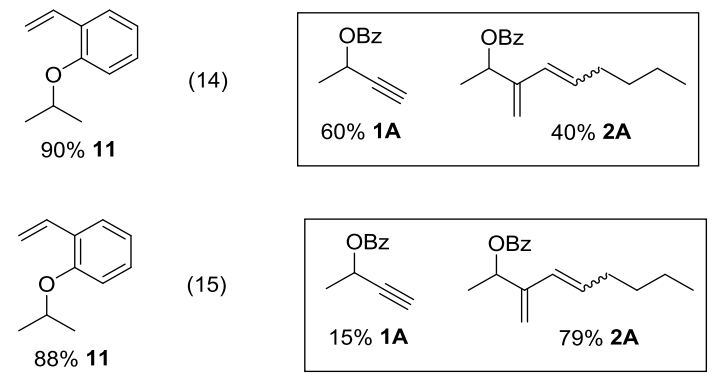

(15)

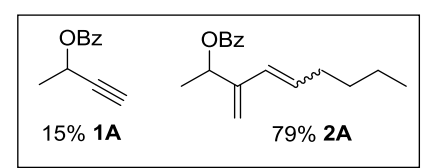

To an oven dried $100 \mathrm{~mL}$ jacketed reaction vessel was added 1-hexene (763 $\mu \mathrm{L}$, $6 \mathrm{mmol}), 1 \mathrm{~A}(83.6 \mathrm{mg}, 0.48 \mathrm{mmol})$ and $5.04 \mathrm{~mL}$ of 1,2-dichloroethane with a magnetic stir bar under an argon atmosphere. The solution was equilibrated at $25{ }^{\circ} \mathrm{C}$ for 15 minutes using a thermostat controlled water circulator. The Hoveyda precatalyst (3.8 $\mathrm{mg}, 0.006 \mathrm{mmol}$ ) was added as a solution in $200 \mu \mathrm{L}$ of 1,2-dichloroethane and allowed to stir for 100 or $200 \mathrm{~s}$. Then the reaction was quenched by the addition of $p$ chlorophenylisocyanide (16.5 mg, $0.12 \mathrm{mmol}, 20$ equiv) in $200 \mu \mathrm{L}$ of toluene. The solvent was then removed by placing under high vacuum while cooling the solution in an ice bath. Once the 1,2-dichloroethane was removed, mesitylene $(0.002 \mathrm{mmol}$, added using a $10 \%$ stock solution in chloroform-d) was added and the product mixture was analyzed by ${ }^{1} \mathrm{H}$ NMR. Conversion was determined by ${ }^{1} \mathrm{H}$ NMR by integration of the product $2 \mathrm{~A}$ ( $E / Z$ mixture) at 5.34 and $5.20 \mathrm{ppm}$ (singlets), the alkyne $1 \mathrm{~A}$ at $2.49 \mathrm{ppm}$ (s) versus mesitylene at $6.8 \mathrm{ppm}$ (s). At $200 \mathrm{~s}$ under these conditions no further alkyne consumption was observed by ReactIR ${ }^{\mathrm{TM}}$. And no significant amount of the Hoveyda precatalyst was trapped by the Buchner insertion reaction. 


\section{Inhibition Studies}

Using the standard kinetic procedure, product inhibition studies were carried out by the addition an equal molar concentration of diene $2 \mathrm{~A}$ at the beginning of the reaction. The comparison is shown in Scheme S8 for the rate of ene-yne metathesis of 1A with 1-hexene. No effect on rate was observed when the diene product was added at the beginning of the reaction. With diene $2 \mathrm{~A}$ present a $k_{\text {obs }}$ value of $0.000274 \mathrm{M} \mathrm{s}^{-1}$ (eq 16) was obtained where as in the absence of diene $2 \mathrm{~A}$, a $k_{\text {obs }}$ value of $0.000267 \mathrm{M}$ $\mathrm{s}^{-1}$ (eq 17) was obtained.

Scheme S8. Product Inhibition Studies

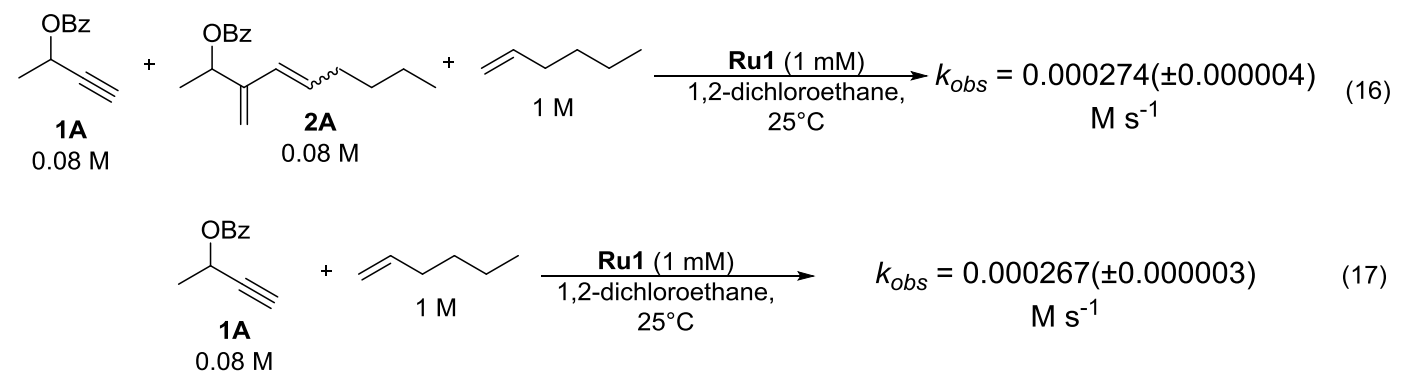

Using the standard kinetic procedure, styrene inhibition studies were carried out by the addition of a varying molar concentration of styrene 11 at the beginning of the reaction. The comparison is shown in Scheme S9. The reactions were run at $0.08 \mathrm{M}$ 1A, 1 M 1-hexene, $1 \mathrm{mM}$ Ru1, and 0-3 mM 11.

Scheme S9. Styrene Inhibition Studies

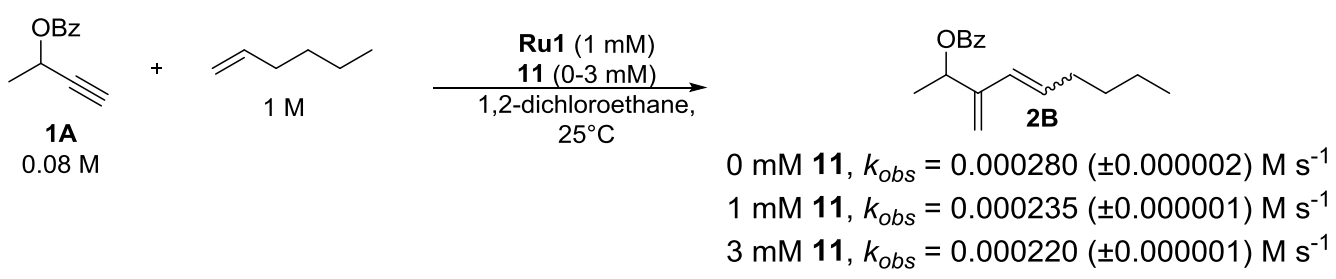

\section{J. Kinetics Treatment}

The lack of trapping of carbenes, the observation of decomposition under EYM conditions and the steady state (SS) of EYM seen in Figures S11 and S12 led us to hypothesize steady state concentrations for both ruthenium carbene intermediates $\mathbf{A}$ and $\mathbf{B}$. The steady-state (SS) assumption is also justified based on the excess alkene used (pseudo-order in alkene), the very low catalyst loadings and the high molar ratio of alkene to precatalyst (as high as 40,000 : 1). Decomposition of active catalyst is especially apparent at the lowest alkene concentrations (see Figure S10), and must be occurring in all EYM studied because the reaction rate does not increase as more 
precatalyst initiates. In most cases, the precatalyst Ru1 has fully initiated before or as the EYM is completed. The experimental rate law was determined to be rate = $k_{E Y M}[\text { Ru1 }]_{0}{ }^{1}$ [alkene] ${ }^{1}$ [alkyne] ${ }^{0}$ and must be properly explained by the kinetic treatment outlined below. The observed first-order dependence in [alkene] and [Ru1] and zeroorder dependence in [alkyne] gives $k_{E Y M}$ that is an apparent second order rate constant. This rate law does not apply to internal alkynes which demonstrated a first-order dependency on the alkyne.

Considering steady state approximations for both carbene intermediates $\mathbf{A}$ and $\mathbf{B}$, and that the alkyne consumption (observed by ReactIR ${ }^{\mathrm{TM}}$ ) occurs at step $k_{1}$, the experimental rate law can be explained. This is a simplified rate treatment that does not include ruthenacyclobutane intermediates which are known to exist in equilibrium with carbene intermediates such as $\mathbf{A}$. The four individual rate constants are defined as: the catalyst initiation, $k_{\text {init; }}$; the first propagation step, $k_{1}$; the second propagation step, $k_{2}$; and the decomposition step, $k_{d e c}$. These are shown in the proposed mechanism presented in Scheme S10. As discussed in the paper, the initiation $\mathrm{k}_{\text {init }}$ is considered to be an alkene-independent rate constant. If $k_{\text {init }}$ was not alkene independent, then the alkene dependence in the experimentally-determined rate law would be greater than one.

Scheme S10. The Working Mechanism of Ene-Yne Metathesis and Relevant Rates/Dependencies
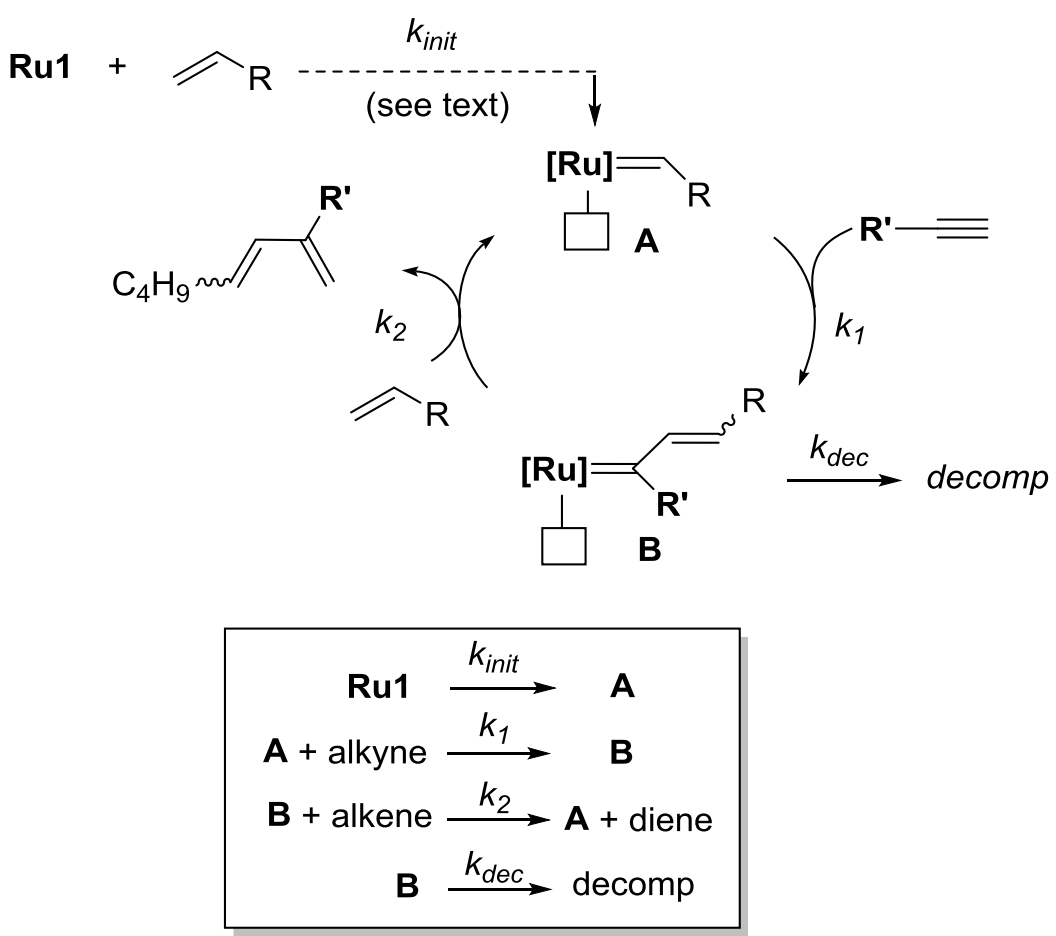
A simplified rate derivation is based on the rate equations shown in the box above. Again $k_{\text {init }}$ is not thought to be alkene dependent; alkene dependency arises in the $k_{2}$ step of ene-yne metathesis. This is discussed in greater detail in the paper.

The steady-state treatment for carbene intermediate $\mathbf{A}$ :

$\frac{d \mathbf{A}}{d t}=0=k_{\text {init }}[\mathbf{R u 1}]-k_{1}[\mathbf{A}][$ alkyne $]+k_{2}[\mathbf{B}][$ alkene $]$

The rate expression:

rate $=\frac{-d[\text { alkyne }]}{d t}=k_{1}[\mathbf{A}][$ alkyne $]$

The steady-state treatment for vinyl carbene intermediate $\mathbf{B}$ :

$\frac{d \mathbf{B}}{d t}=0=k_{1}[\mathbf{A}][$ alkyne $]-k_{2}[\mathbf{B}][$ alkene $]-k_{d e c}[\mathbf{B}]$

Setting eq 1 equal to eq 3 gives:

$k_{\text {init }}[\mathrm{Ru} 1]=k_{\text {dec }}[\mathrm{B}](4)$

Solving for $[\mathbf{B}]$,

$[\mathbf{B}]=\frac{k_{\text {init }}[\mathbf{R u} \mathbf{1}]}{k_{\text {dec }}}$

Plugging this expression for $[\mathbf{B}]$ into eq 3 gives:

$k_{1}[\mathbf{A}][$ alkyne $]=\frac{k_{\text {init }} k_{2}}{k_{\text {dec }}}[\mathbf{R u 1}][$ alkene $]+k_{\text {init }}[\mathbf{R u 1}]$

Equating eq 2 and eq 6 gives:

rate $=\frac{-d[\text { alkyne }]}{d t}=\frac{k_{\text {init }} k_{2}}{k_{\text {dec }}}[\mathbf{R u 1}][$ alkene $]+k_{\text {init }}[\mathbf{R u 1}]$

Since,

$\frac{k_{\text {init }} k_{2}}{k_{\text {dec }}}[\mathbf{R u} \mathbf{1}][$ alkene $] \gg k_{\text {init }}[\mathbf{R u} \mathbf{1}]$

The rate expression becomes:

rate $=\frac{-d[\text { alkyne }]}{d t}=\frac{k_{\text {init }} k_{2}}{k_{d e c}}[\mathbf{R u 1}][$ alkene $]$ 


\section{K. NMR Spectra}

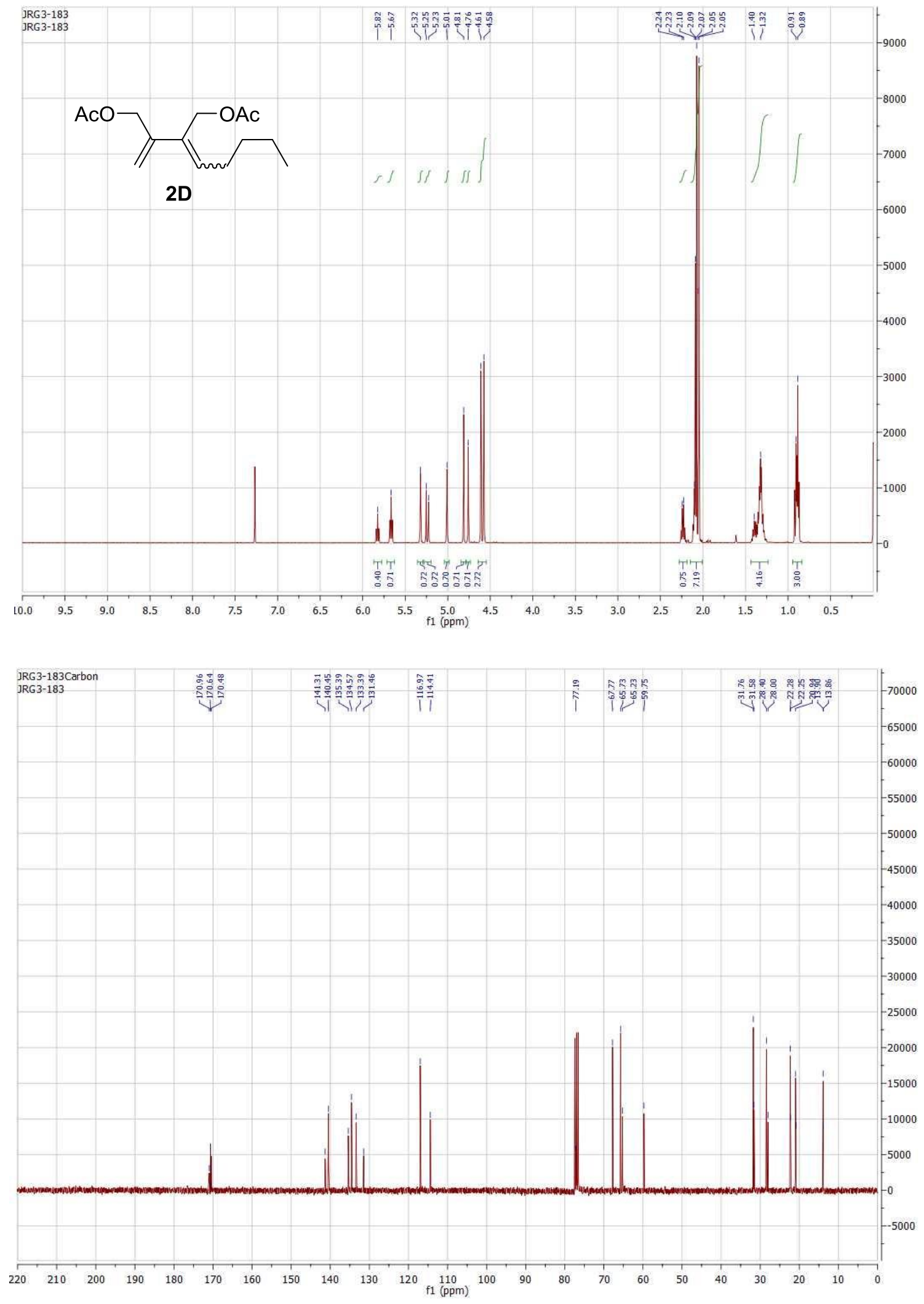




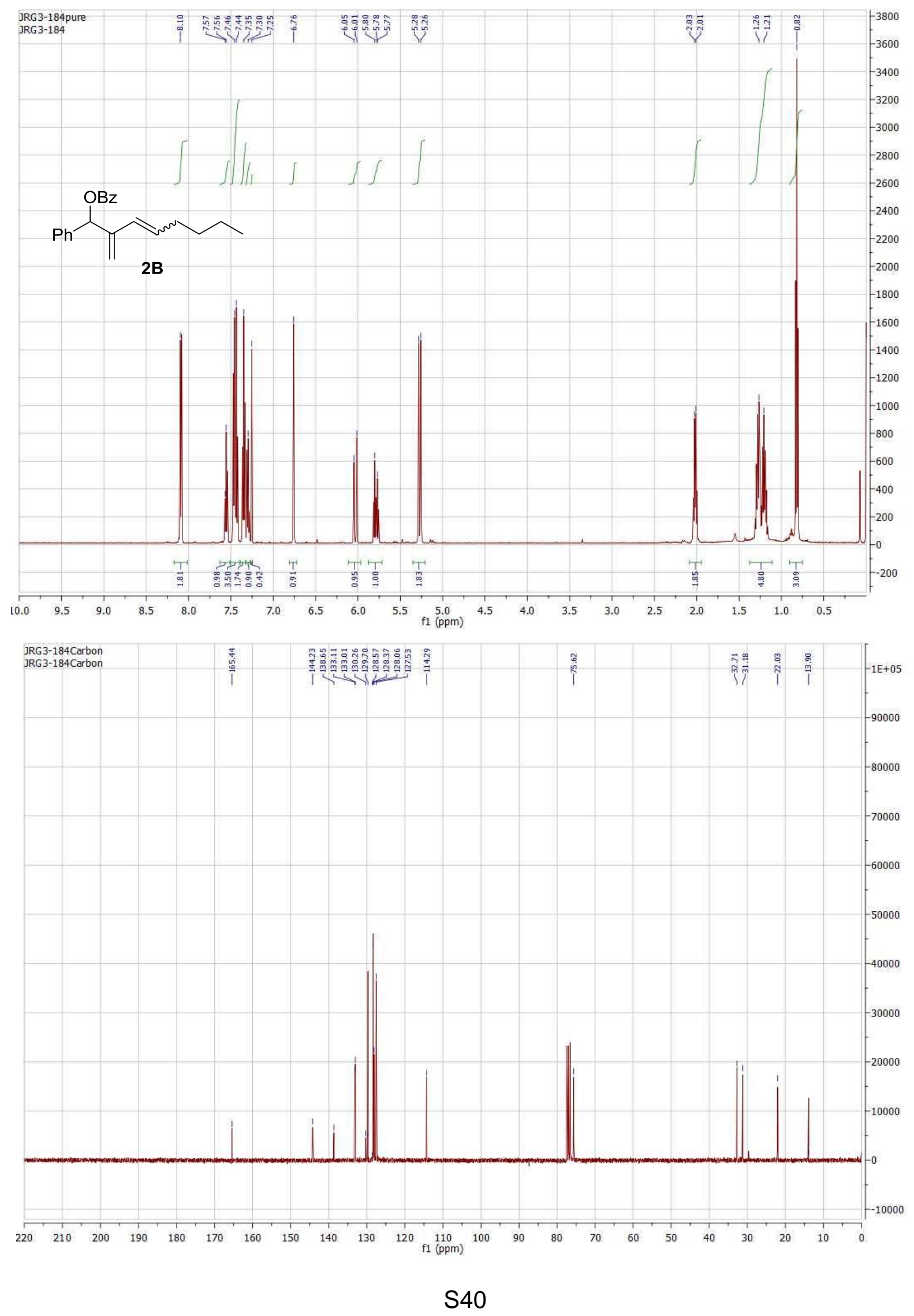




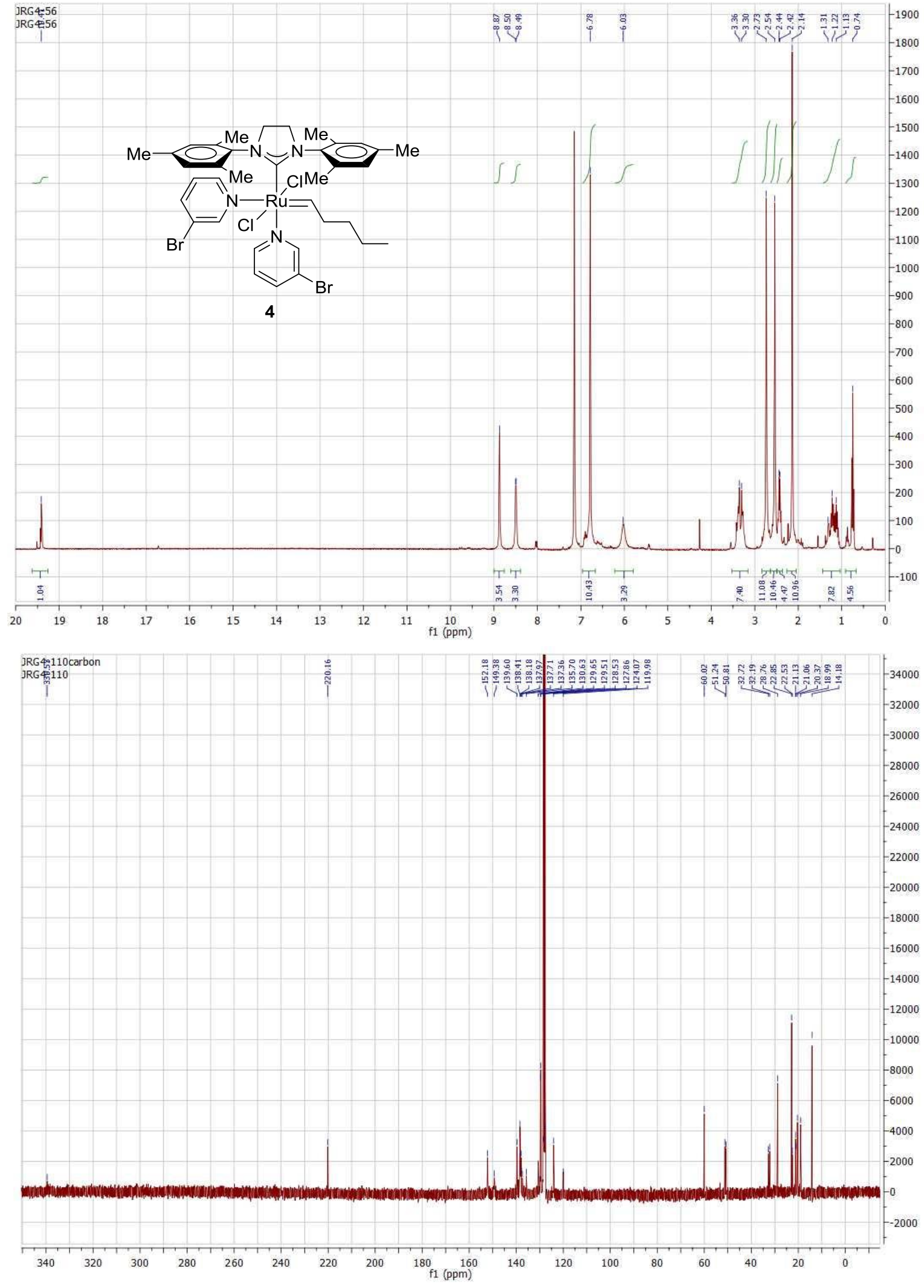




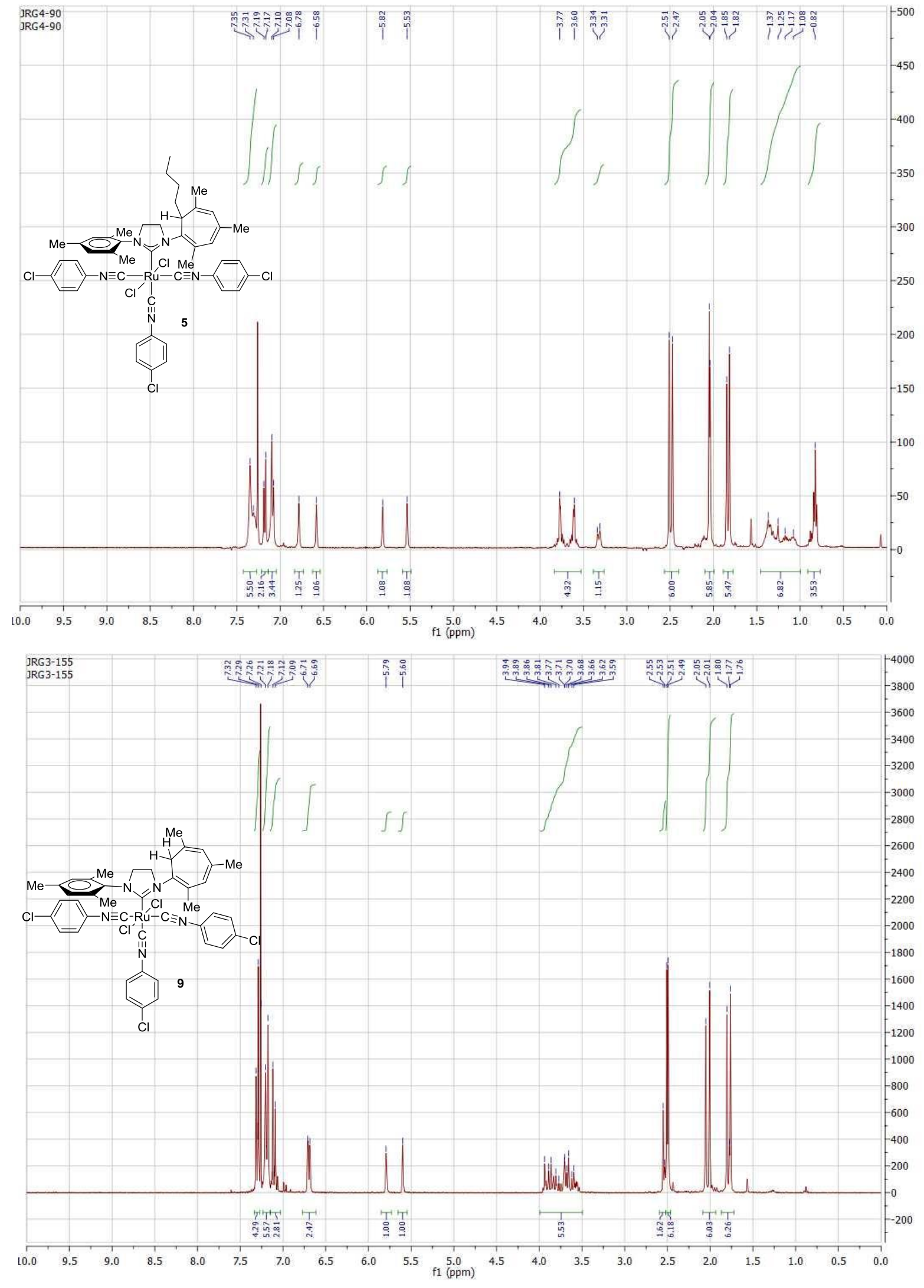


References

(1) Kulkarni, A. A.; Diver, S. T. Org. Synth. 2006, 83, 200.

(2) Wang, Y.-H.; Liu, H.; Zhu, L.-L.; Li, X.-X.; Chen, Z. Adv. Synth. Catal. 2011, 353, 707. 2688.

(3) Riss, P. J.; Hummerich, R.; Schloss, P. Org. Biomol. Chem. 2009, 7,

(4) Galan, B. R.; Gembicky, M.; Dominiak, P. M.; Keister, J. B.; Diver, S. T. J. Am. Chem. Soc. 2005, 127, 15702.

(5) Vorfalt, T.; Wannowius, K.-J.; Plenio, H. Angew. Chem. Int. Ed. 2010, 49, 5533.

(6) Love, J. A.; Morgan, J. P.; Trnka, T. M.; Grubbs, R. H. Angew. Chem. Int. Ed. 2002, 41, 4035. 2013.

(7) Williams, J. E.; Harner, M. J.; Sponsler, M. B. Organometallics 2005, 24, 